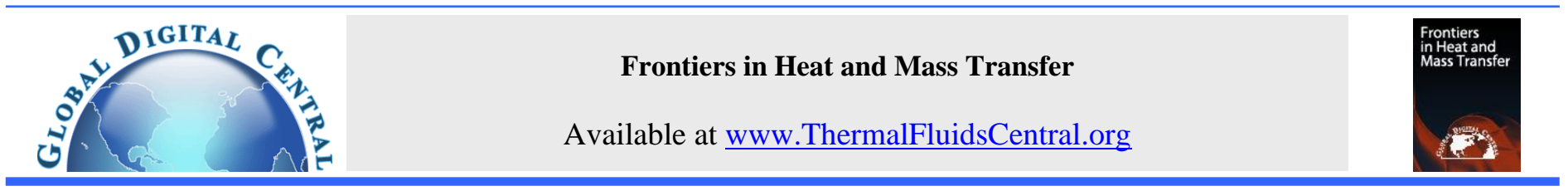

\title{
FLOW AND HEAT TRANSFER CHARACTERISTICS OF AIR IN SQUARE CHANNEL HEAT EXCHANGER WITH C-SHAPED BAFFLE: A NUMERICAL STUDY
}

\author{
Amnart Boonloi ${ }^{\mathrm{a}}$ and Withada Jedsadaratanachai, ${ }^{\mathrm{b}, *}$ \\ ${ }^{a}$ Department of Mechanical Engineering Technology, College of Industrial Technology, King Mongkut's University of Technology North Bangkok, \\ Bangkok 10800, Thailand \\ ${ }^{b}$ Department of Mechanical Engineering, Faculty of Engineering, King Mongkut's Institute of Technology Ladkrabang, Bangkok 10520, Thailand
}

\begin{abstract}
The purpose of the present work is to study flow configuration and heat transfer behavior in a square channel heat exchanger equipped with C-shaped baffle. The influences of flow attack angle and baffle size on flow and heat transfer characteristics are considered for the laminar flow regime with the Reynolds number around 100 - 2000. The numerical study with finite volume method is selected for the present investigation. The SIMPLE algorithms is opted to solve the numerical problem. The numerical results are concluded in terms of flow and heat transfer mechanisms in the tested section. The thermal performance analysis; Nusselt number ratio $\left(\mathrm{Nu} / \mathrm{Nu}_{0}\right)$, friction factor $\left(\mathrm{f} / \mathrm{f}_{0}\right)$ and thermal enhancement factor $(\mathrm{TEF})$, are also summarized. The numerical model of the smooth square channel is validated with the correlations on both Nusselt number and friction factor. The numbers of grid cell for the computational domain are also compared. The numerical results reveal that the C-shaped baffle in the tested section leads to the appearance of the thermal boundary layer disturbance on the channel walls that the important cause for heat transfer rate and thermal efficiency enhancements. The maximum TEF of the square duct with $\mathrm{C}$-shaped baffle is around 3.89. In addition, the optimum gap spacing value for the square channel inserted with C-shaped baffle is around $5 \%$.
\end{abstract}

Keywords: C-shaped baffle; thermal performance; heat transfer; Nusselt number; numerical study.

\section{INTRODUCTION}

The enhancements of the heat transfer rate and thermal performance in various types of heat exchangers or engineering devices had been done by two methods; active and passive methods. In the present research, the passive method is focused. The passive method is not required the additional power to augment heat transfer rate. The passive method is to generate the vortex flow, swirling flow, impinging flow in the heating section and also increases the turbulent mixing of the tested fluid. These phenomena is the reason for heat transfer and thermal efficiency enhancements. The device, which generates the vortex flow/swirling flow, is called vortex generators or turbulators. Rib, baffle, conical ring, wing, winglet, etc., are types of the vortex generators.

Many researchers reported about the heat transfer rate, pressure loss and thermal performance in heat exchanger with various vortex generators. For examples, Boonloi (2014) numerically studied the effects of $20^{\circ} \mathrm{V}$-rib on flow and heat transfer in a square duct. The influences of rib height and flow direction were considered for the $\mathrm{Re}=100-2000$. Boonloi (2014) found that the best thermal performance is around 4.2. Jedsadaratanachai and Boonloi (2014) studied the thermo-hydraulic performance in the heat exchanger square channel with $30^{\circ}$ double Vbaffle. They concluded that the best thermo-hydraulic performance is around 3.2. The numerical study on flow and heat transfer in a circular tube with $45^{\circ} \mathrm{V}$-baffle was reported by Jedsadaratanachai et al. (2015). The effects of flow direction and baffle height on thermal performance were considered for $\operatorname{Re}=100-2000$. They summarized that the best thermal performance of the heat exchanger tube with V-baffle is around
3.2. Kumar and Layek (2018a) presented the Nusselt number and friction loss for a twisted rib roughened rectangular duct by liquid crystal technique. Kumar et al. (2017a) experimentally investigated on Nusselt number and friction factor for discretized broken V-baffle in a solar air channel. The width to height ratio, relative baffle gap distance, relative baffle gap width, relative baffle height, relative baffle pitch and flow attack angle of the baffled channel were considered. Kumar et al. (2017b) experimentally examined the heat transfer rate and pressure loss augmentations in a solar channel with discretized broken V-pattern baffle. They pointed out that the optimal thermal performance for the channel with V-baffle is around 3.14. Kumar and Layek (2018b) experimentally examined the influences of relative roughness pitch, inclination angle and twist ratio on flow and heat transfer in a solar air heater channel for $\mathrm{Re}=3500-21,000$. The thermal performance analysis for laminar flow in a square channel with $30^{\circ} \mathrm{V}$-baffle was presented by Boonloi and Jedsadaratanachai (2014). They claimed that the V-baffle in the channel gives thermal enhancement factor around 4.25. Boonloi and Jedsadaratanachai (2016) numerically presented the discrete combined $\mathrm{V}$-baffle and $\mathrm{V}$-orifice in a square channel on convective heat transfer for $\operatorname{Re}=5000-20,000$. They detected that the increment on heat transfer rate is around 2.8 - 6.0 time higher than the plain channel. Gormaa et al. (2017) reported the enhancement of cooling characteristics for a triple concentric tube fitted with rib. The parameter optimization of a solar air collector with holes on baffle was reported by $\mathrm{Hu}$ et al. (2018). Li et al. (2018) simulated the thermal performance in a channel with multi Vbaffle for turbulent flow regime. Menasria et al. (2017) numerically studied the thermo-hydraulic performance in a solar air heater duct fitted with novel rectangular baffle with high aspect ratio. They found that the 
heat transfer and friction factor in the solar air heater duct are around 2.16 and 15.95 times above the smooth duct, respectively. They also reported that the greatest thermo-hydraulic performance factor in the solar air heater duct is around 0.857. Promvonge (2010), Promvonge and Kwankaomeng (2010) and Promvonge et al. (2012) claimed that the baffle or thin rib has high effectiveness to enhance heat transfer rate in the heating system, especially, V-shaped baffle and inclined baffle.

In the present work, the C-shaped baffle is created. The C-shaped baffle are modified from the inclined baffle with inline arrangement (placed on the upper and lower walls of the channel). The gap spacing between outer edges of the baffle and the channel walls is generated to reduce pressure loss in the tested section and also helps to induce the turbulent mixing of the fluid flow. The numerical investigation with commercial code is selected for the present work. The numerical result can describe the mechanisms in the tested section. The understanding on mechanisms in the tested section is important factor to improve the heat exchanger.

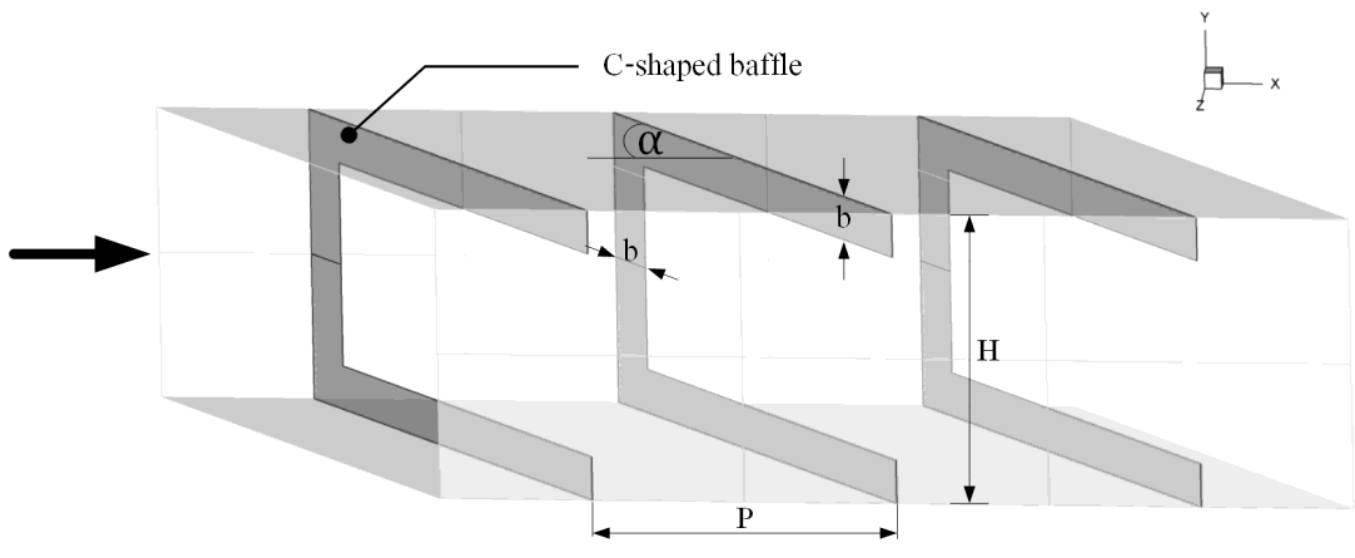

(a)

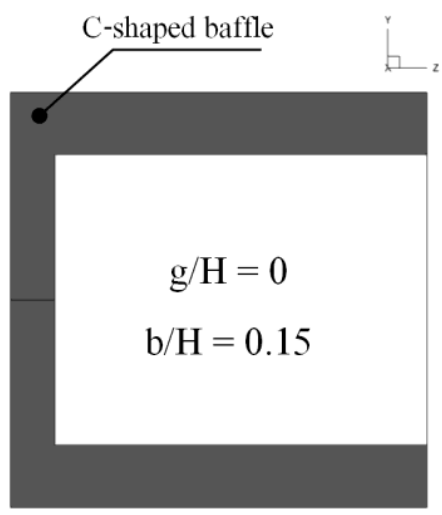

(b)

Fig. 1 (a) channel inserted with $\mathrm{C}$-shaped baffle (at $\mathrm{g} / \mathrm{H}=0$ and $\mathrm{b} / \mathrm{H}=0.15)$ and (b) physical domain in $\mathrm{y}-\mathrm{z}$ plan $(\mathrm{at} \mathrm{g} / \mathrm{H}=0$ and $\mathrm{b} / \mathrm{H}=0.15)$.

The influences of the baffle height, flow attack angle, gap spacing for the C-shaped baffle on heat transfer rate, pressure loss and thermal performance are studied. The laminar flow regime with the Reynolds number in the range $100-2000$ is considered. The numerical results for the square channel heat exchanger equipped with $\mathrm{C}$-shaped baffle are reported in terms of streamline, longitudinal flow, temperature contour and local Nusselt number contour. The numerical results are also concluded in forms of Nusselt number ratio $(\mathrm{Nu} / \mathrm{Nu}$ ) $)$, friction factor ratio $\left(\mathrm{f} / \mathrm{f}_{0}\right)$ and thermal enhancement factor (TEF).

\section{METHODOLOGY}

\subsection{Physical domain}

The physical domain for the square channel inserted with $\mathrm{C}$-shaped baffle is presented as Figs. 1 and 2 for $\mathrm{g} / \mathrm{H}=0$ (no gap spacing) and $\mathrm{g} / \mathrm{H}$ $=0.15$, respectively. The influences of baffle height, flow attack angle and gap spacing on heat transfer and flow structure are investigated numerically for the laminar regime $(\operatorname{Re}=100-2000)$. The baffle height represents with "b", while b/H or BR is called "blockage ratio". The gap spacing between the outer edges of baffle and the channel wall represents with "g". g/H or GR is named "gap spacing ratio". The blockage ratio is varied in the range $0.05-0.30$, while the gap spacing ratio is varied in the range $0-0.30$. The distance between the baffle is "P". The pitch spacing ratio or $\mathrm{P} / \mathrm{H}$ is fixed at 1 in all investigated cases. The flow attack angles of the $\mathrm{C}$-shaped baffle is separated into 2 groups; $30^{\circ}$ and $45^{\circ}$.

\subsection{Assumption, boundary condition and initial condition}

The flow and heat transfer in the heating section are assumed to be steady in three dimensions. The flow is incompressible and laminar with the Reynolds number around 100-2000 (at the inlet condition). The thermal properties of the tested fluid (air) are constant at the average bulk mean temperature. The convective heat transfer is considered, while the radiation and natural convection are disregarded. The body forced and viscous dissipation is ignored.

The periodic condition (Patankar et al. (1998)) on flow and heat transfer is set for the inlet and outlet of the computational domain. The $\mathrm{C}$-shaped baffle is set as insulator. The uniform temperature around $310 \mathrm{~K}$ is set for all sides of the square channel walls. The temperature of the tested fluid is set around $300 \mathrm{~K}$ at the inlet. The commercial program (FLUENT) is selected to solve the present problem.

\subsection{Mesh development}

The computational models of the duct heat exchanger inserted with the $\mathrm{C}$-shaped baffle with mesh are plotted as Figs. 3a and b, respectively, for $\mathrm{g} / \mathrm{H}=0$ and 0.15 , at $\mathrm{b} / \mathrm{H}=0.15$ and $\alpha=45^{\circ}$. The hexahedron mesh is applied for the numerical model in all investigated cases. The comparison for the number of grid system is done in this part. The five sets of grid; $80000,120000,160000,240000$ and 360000, for the case $\mathrm{BR}=\mathrm{GR}=0.15$ with $\alpha=30^{\circ}$ are compared (see Fig. 4). As the result, the grid around $120000-360000$ gives similar values for both Nusselt number and friction factor. Therefore, the grid around 120000 is selected for all investigated cases when considered both time for investigation and accuracy result.

\subsection{Verification of the smooth tube}

Fig. 5 reports the verification of the smooth duct on both Nusslet number and friction factor. The values of the Nusselt number and friction factor for the smooth channel are compared with the values from the correlations (Cengel and Ghajar (2015)). The deviations of the numerical results are within $\pm 0.03 \%$ on both Nusselt number and friction factor. Therefore, it can be concluded that the numerical model has more reliability to predict flow and heat transfer in the tested channel. 


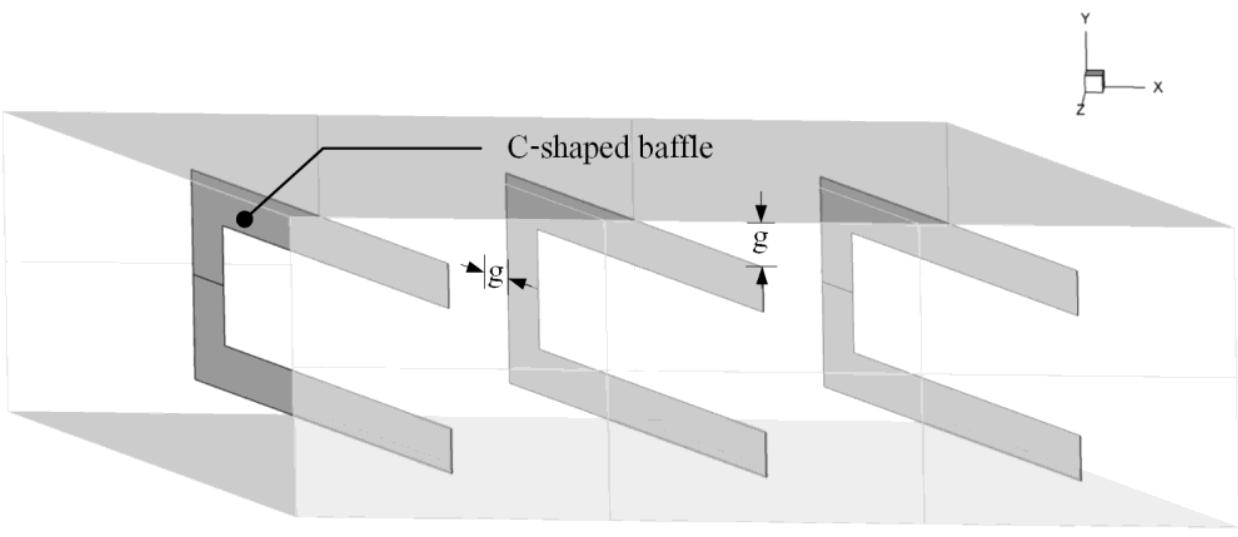

(a)

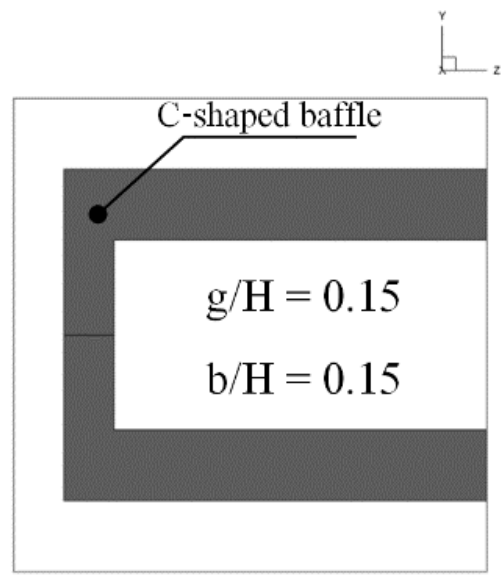

(b)

Fig. 2 (a) channel inserted with $\mathrm{C}$-shaped baffle (at $\mathrm{g} / \mathrm{H}=0.15$ and $\mathrm{b} / \mathrm{H}=0.15$ ) and (b) physical domain in $\mathrm{y}-\mathrm{z}$ plan (at $\mathrm{g} / \mathrm{H}=0.15$ and $\mathrm{b} / \mathrm{H}=0.15)$.

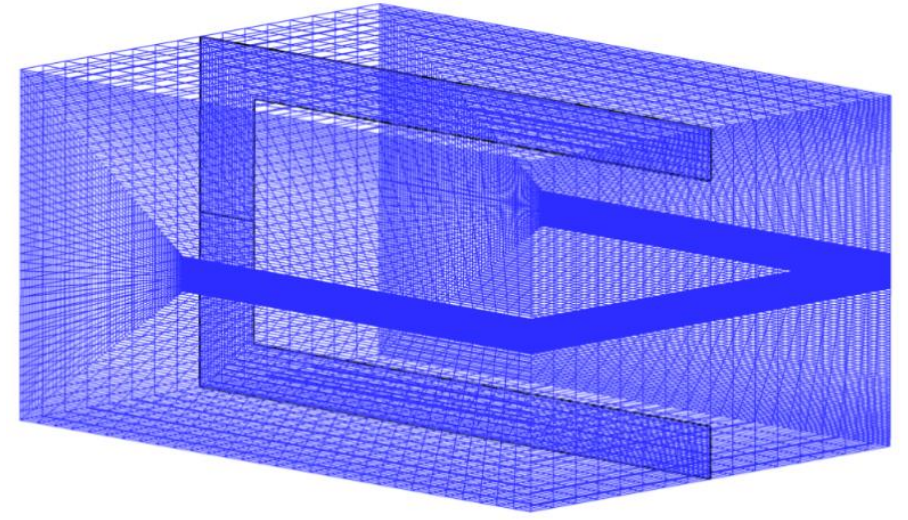

(a)

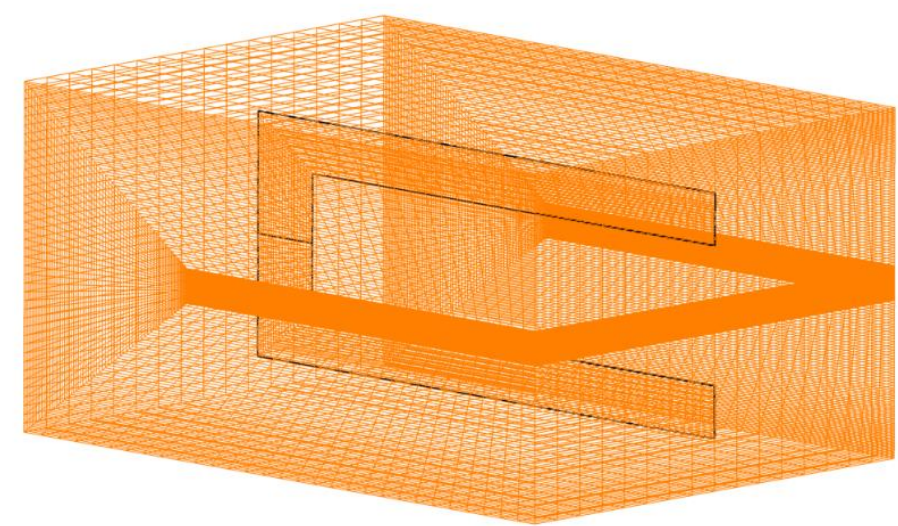

(b)

Fig. 3 Computational domain of square channel fitted with $\mathrm{C}$-shaped baffle for (a) $\mathrm{g} / \mathrm{H}=0$ and (b) $\mathrm{g} / \mathrm{H}=0.15$ at $\mathrm{b} / \mathrm{H}=0.15$ and $\alpha=45^{\circ}$.

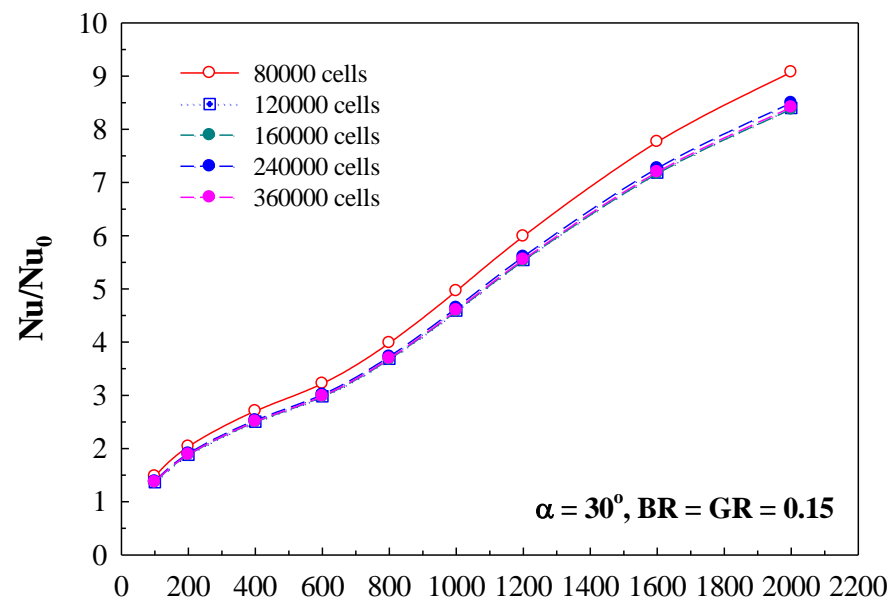

Re

(a)

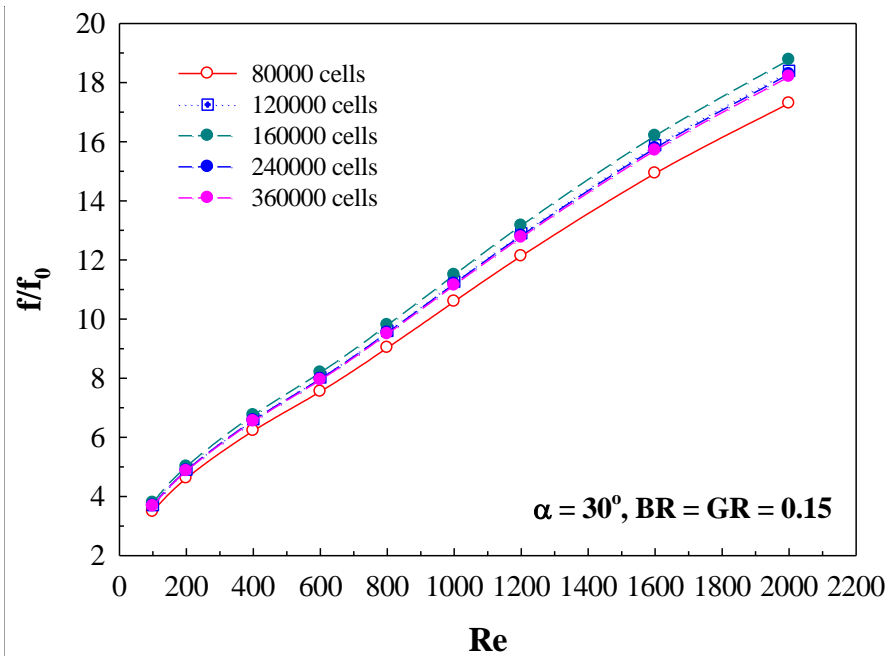

(b)

Fig. 4 Grid independence for (a) $\mathrm{Nu} / \mathrm{Nu}_{0}$ and (b) $\mathrm{f} / \mathrm{f}_{0}$. 


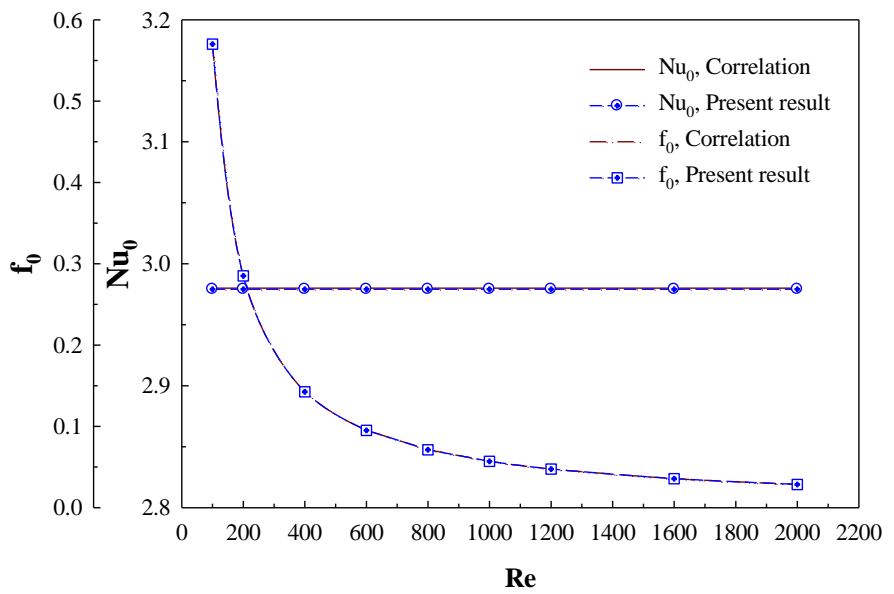

Fig. 5 Verification of the smooth duct for Nusselt number and friction factor.

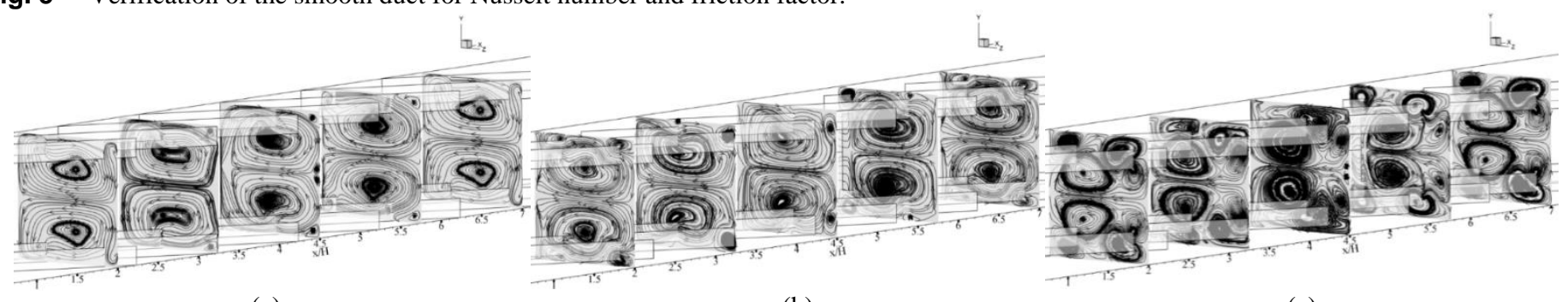

(a)

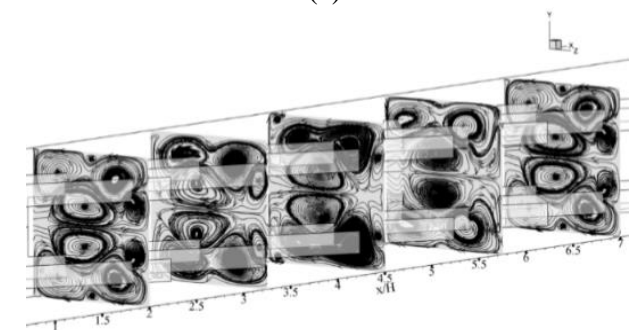

(d) (b)

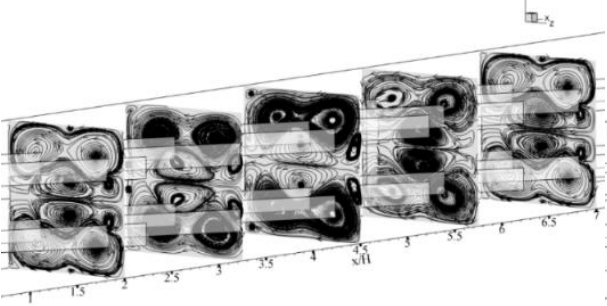

(e) (c)

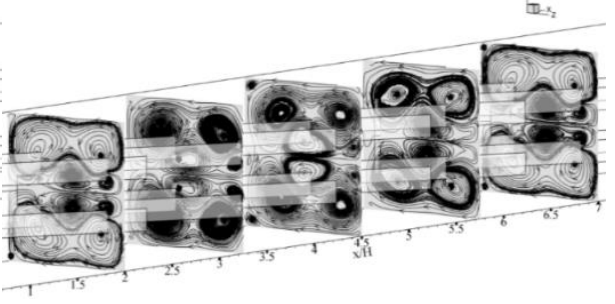

(f)

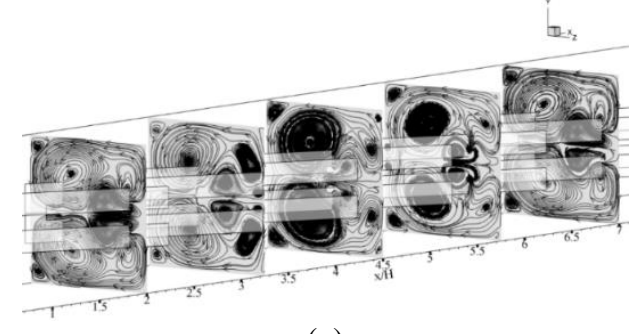

(g)

Fig. 6 Streamline in $y-z$ plans of the channel inserted with C-shaped baffle for (a) $g / H=0,(b) g / H=0.05$, (c) $g / H=0.10$, (d) $g / H=0.15$, (e) $g / H=$ 0.20 , (f) $\mathrm{g} / \mathrm{H}=0.25$ and (g) $\mathrm{g} / \mathrm{H}=0.30$ at $\mathrm{b} / \mathrm{H}=0.15, \alpha=30^{\circ}$ and $\mathrm{Re}=800$.

\section{MATHEMATICAL FOUNDATION AND NUMERICAL METHOD}

The mathematical foundation and numerical method for the present work are referred from Promvonge et al. (2012). The numerical problem is sloved by the commercial code (finite volume method with SIMPLE algorithm).

The important variables in term of dimensionless for the present research are Reynolds number, friction factor, Nusselt number and thermal enhancement factor. The air velocity is reported in term of the Reynolds number, which can be printed as Eq. 1.

$\operatorname{Re}=\frac{\rho \bar{u} D_{h}}{\mu}$
The pressure loss across the tested section is concluded in terms of the friction factor value. Eq. 2 shows the calculations of the friction factor across the heating section.

$$
f=\frac{(\Delta P / L) D_{h}}{\frac{1}{2} \rho \bar{u}^{2}}
$$

The heat transfer rate is presented with the local Nusselt number $\left(\mathrm{Nu}_{\mathrm{x}}\right)$ and average Nusselt number $(\mathrm{Nu})$. The calculations of the local Nusselt number and the average Nusselt number are illustrated as Eqs. 3 and 4 , respectively.

$$
\begin{aligned}
& N u_{x}=\frac{h_{x} D_{h}}{k} \\
& N u=\frac{1}{L} \int N u_{x} \partial x
\end{aligned}
$$


The thermal performance in the heat exchanger square channel is shown with the thermal enhancement factor or TEF. The TEF can determine as Eq. 5.

$$
T E F=\left.\frac{h}{h_{0}}\right|_{p p}=\left.\frac{N u}{N u_{0}}\right|_{p p}=\left(N u / N u_{0}\right) /\left(f / f_{0}\right)^{1 / 3}
$$

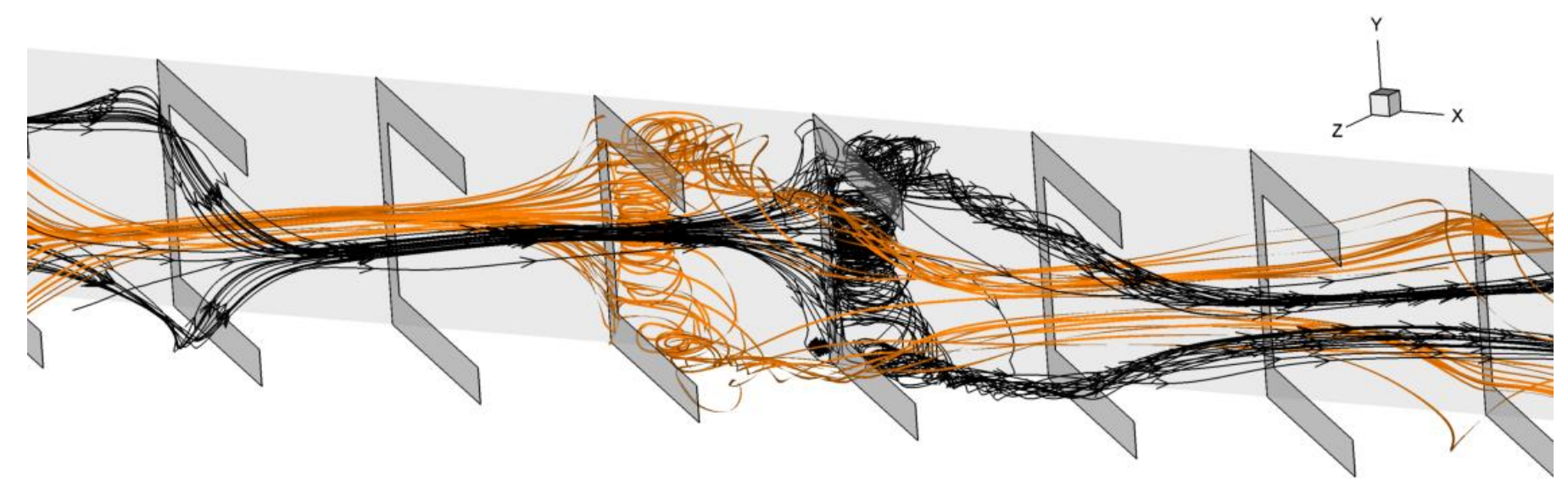

(a)

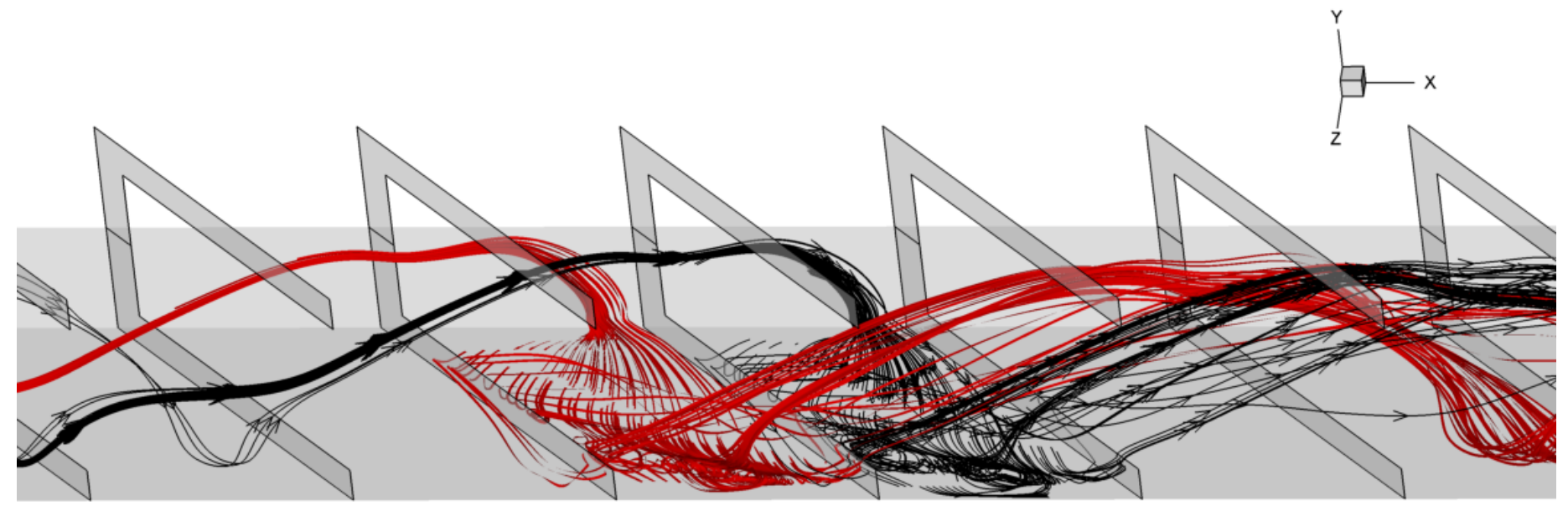

(b)

Fig. 7 Longitudinal vortex flow in channel inserted with $45^{\circ} \mathrm{C}$-shaped baffle at $\mathrm{b} / \mathrm{H}=0.15, \mathrm{~g} / \mathrm{H}=0$ and $\mathrm{Re}=800$ for (a) on sidewall and (b) on lower wall.

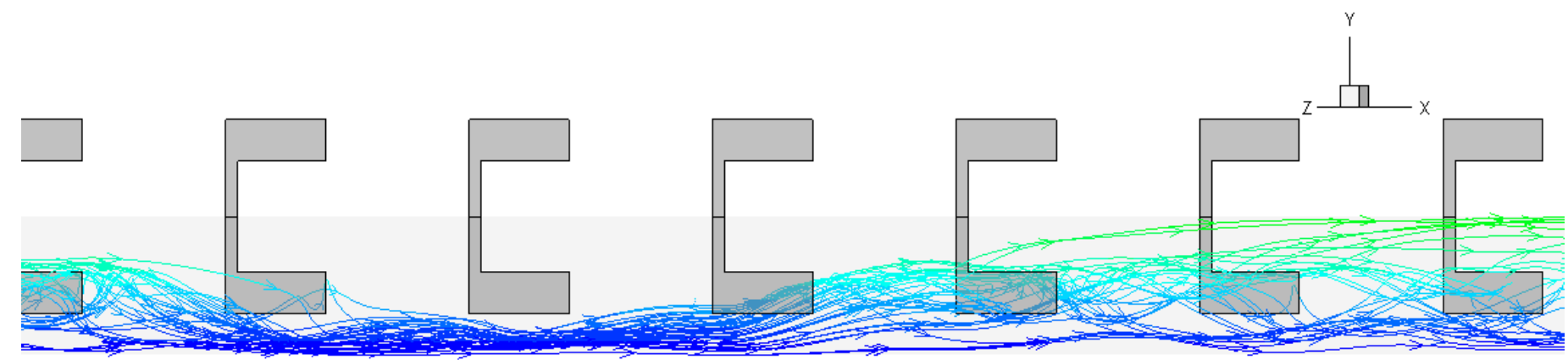

Fig. 8 Longitudinal vortex flow in channel inserted with $45^{\circ} \mathrm{C}$-shaped baffle at $\mathrm{b} / \mathrm{H}=0.15, \mathrm{~g} / \mathrm{H}=0.15$ and $\mathrm{Re}=800$. 


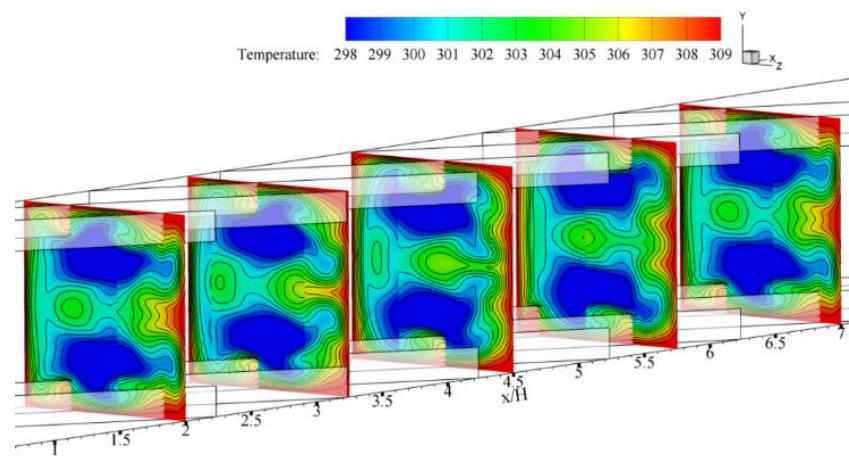

(a)

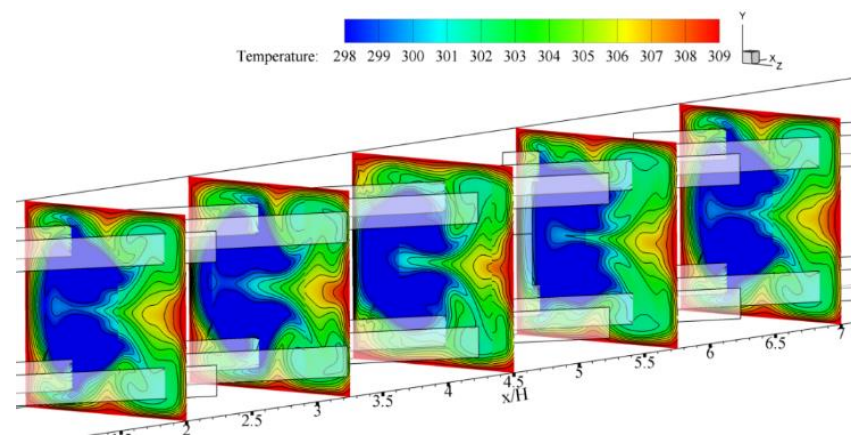

(c)

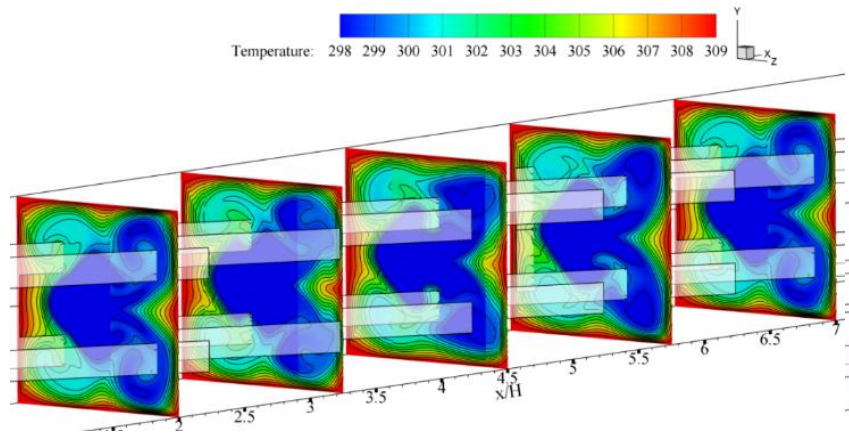

(e)

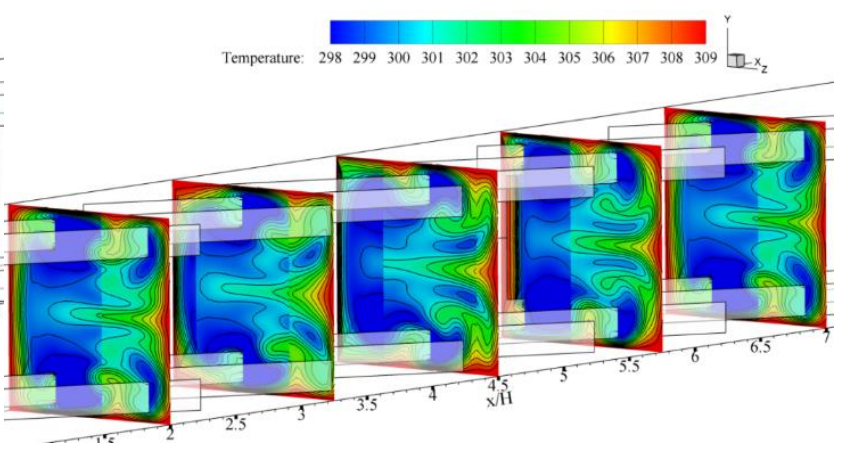

(b)

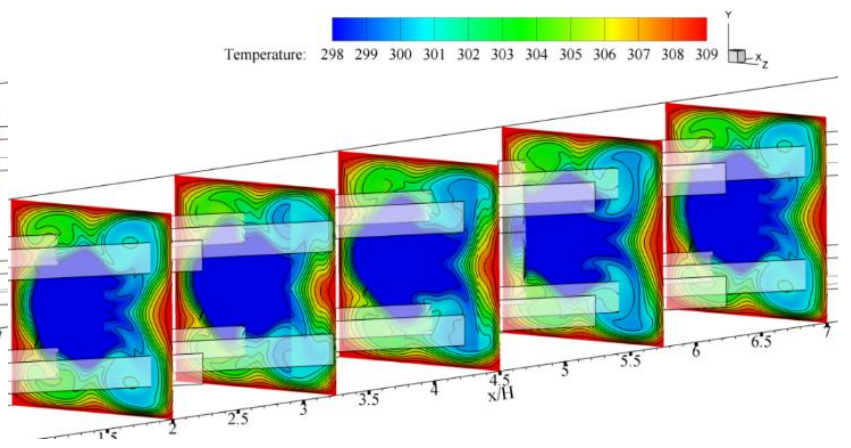

(d)

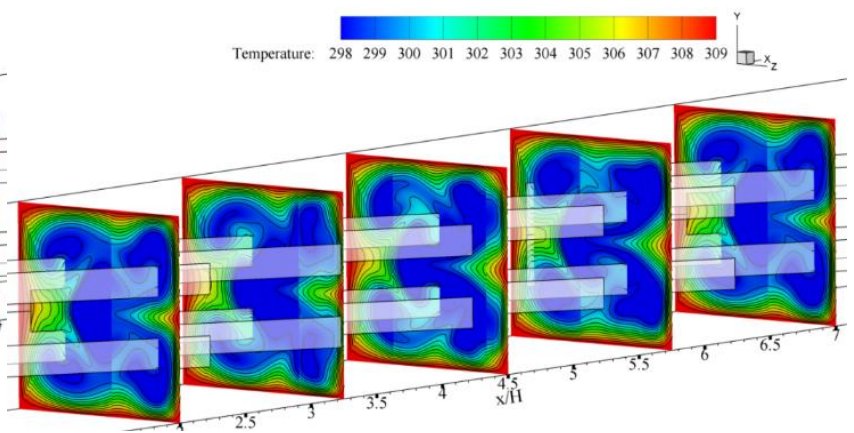

(f)

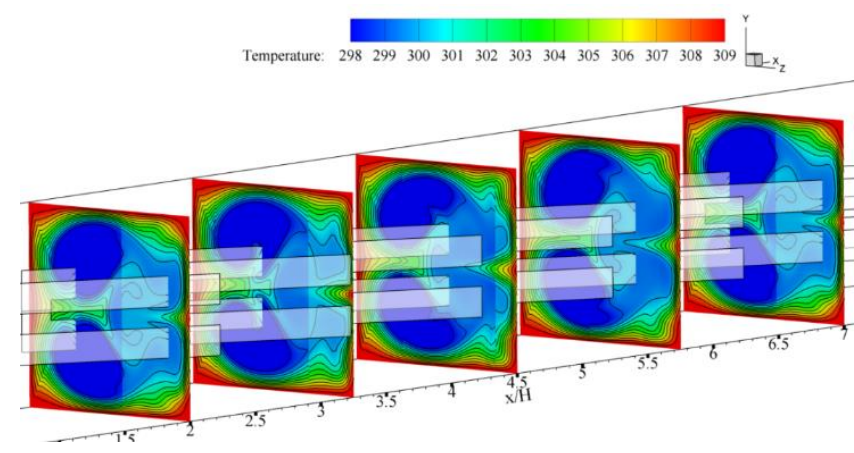

(g)

Fig. 9 Temperature contour in y-z plans of the channel inserted with C-shaped baffle for (a) $g / H=0,(b) g / H=0.05$, (c) $g / H=0.10,(d) g / H=0.15$, (e) $\mathrm{g} / \mathrm{H}=0.20$, (f) $\mathrm{g} / \mathrm{H}=0.25$ and (g) $\mathrm{g} / \mathrm{H}=0.30$ at $\mathrm{b} / \mathrm{H}=0.15, \alpha=30^{\circ}$ and $\mathrm{Re}=800$. 


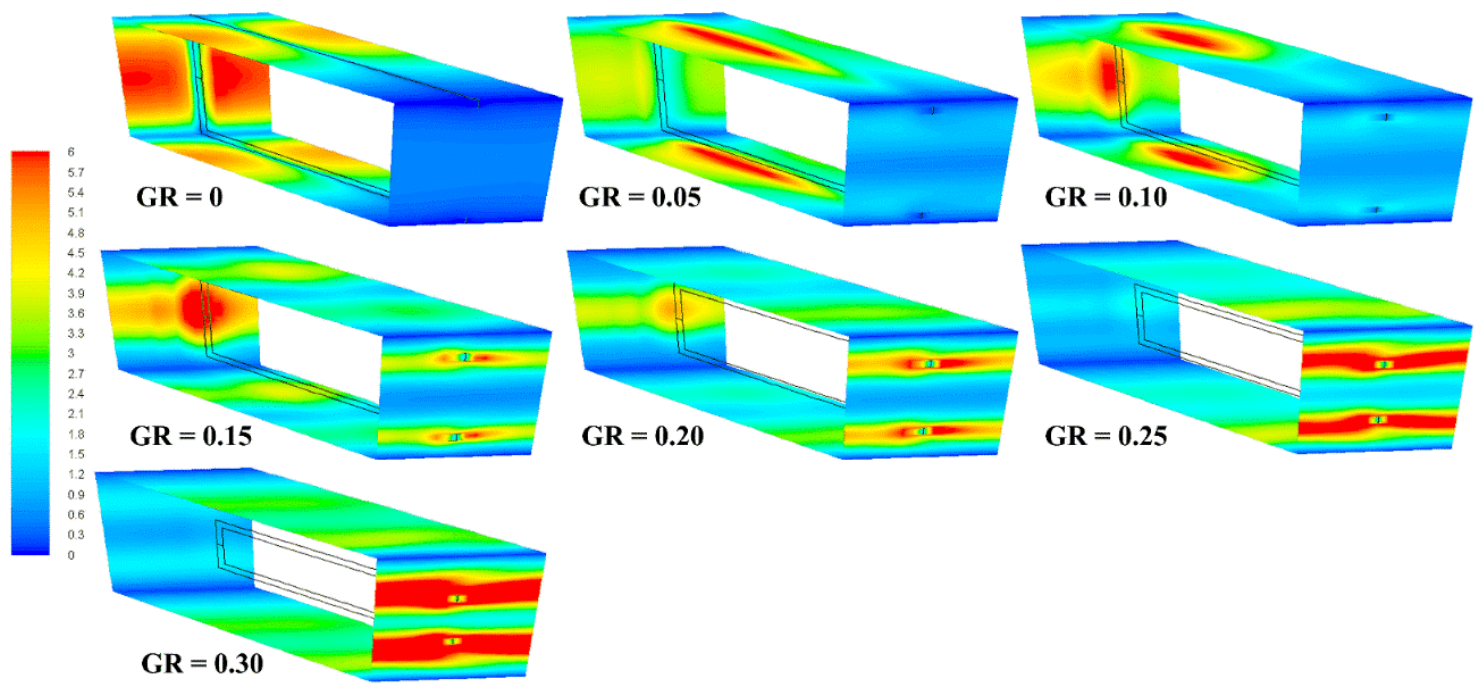

Fig. $10 \mathrm{Nu}_{\mathrm{x}}$ contour for channel inserted with $30^{\circ} \mathrm{C}$-shaped baffle at $\mathrm{BR}=0.05$.
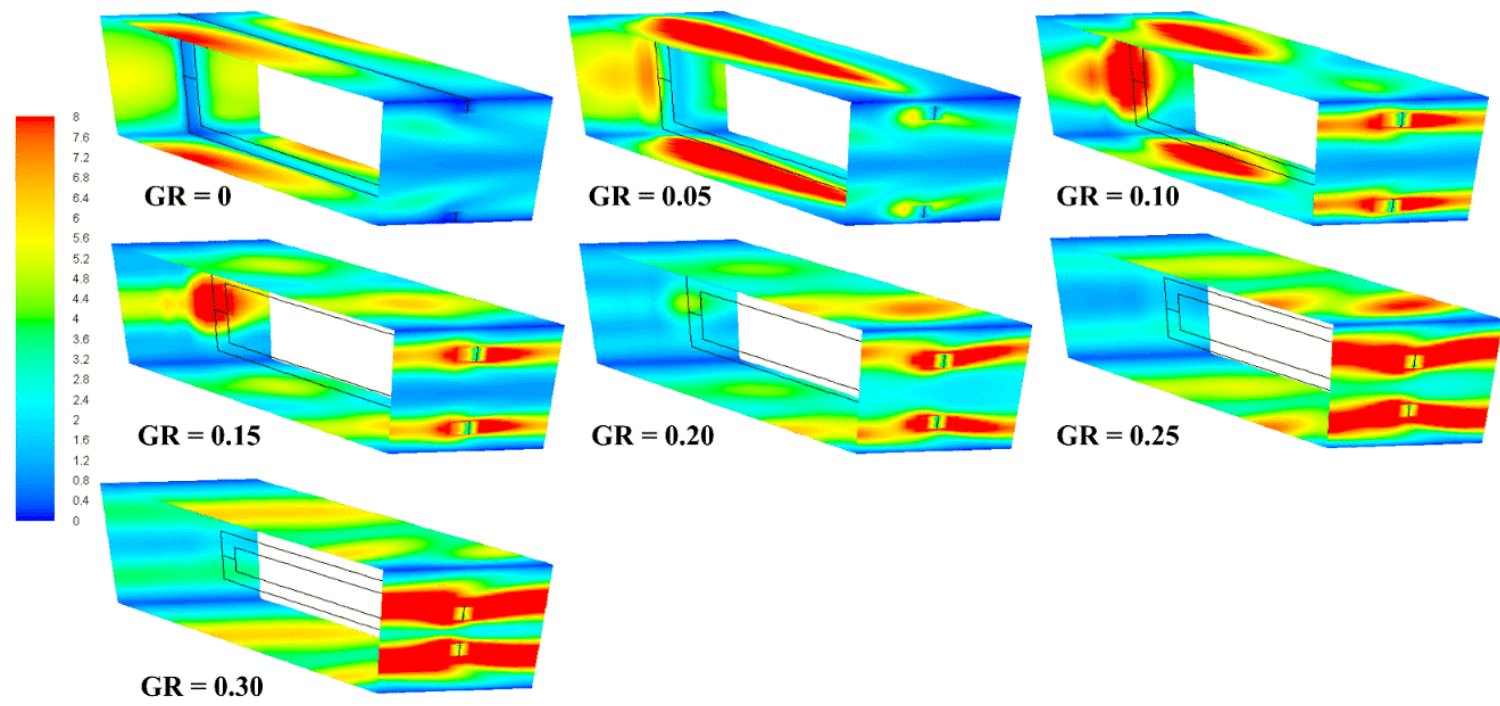

Fig. $11 \mathrm{Nu}_{\mathrm{x}}$ contour for channel inserted with $30^{\circ} \mathrm{C}$-shaped baffle at $\mathrm{BR}=0.10$.

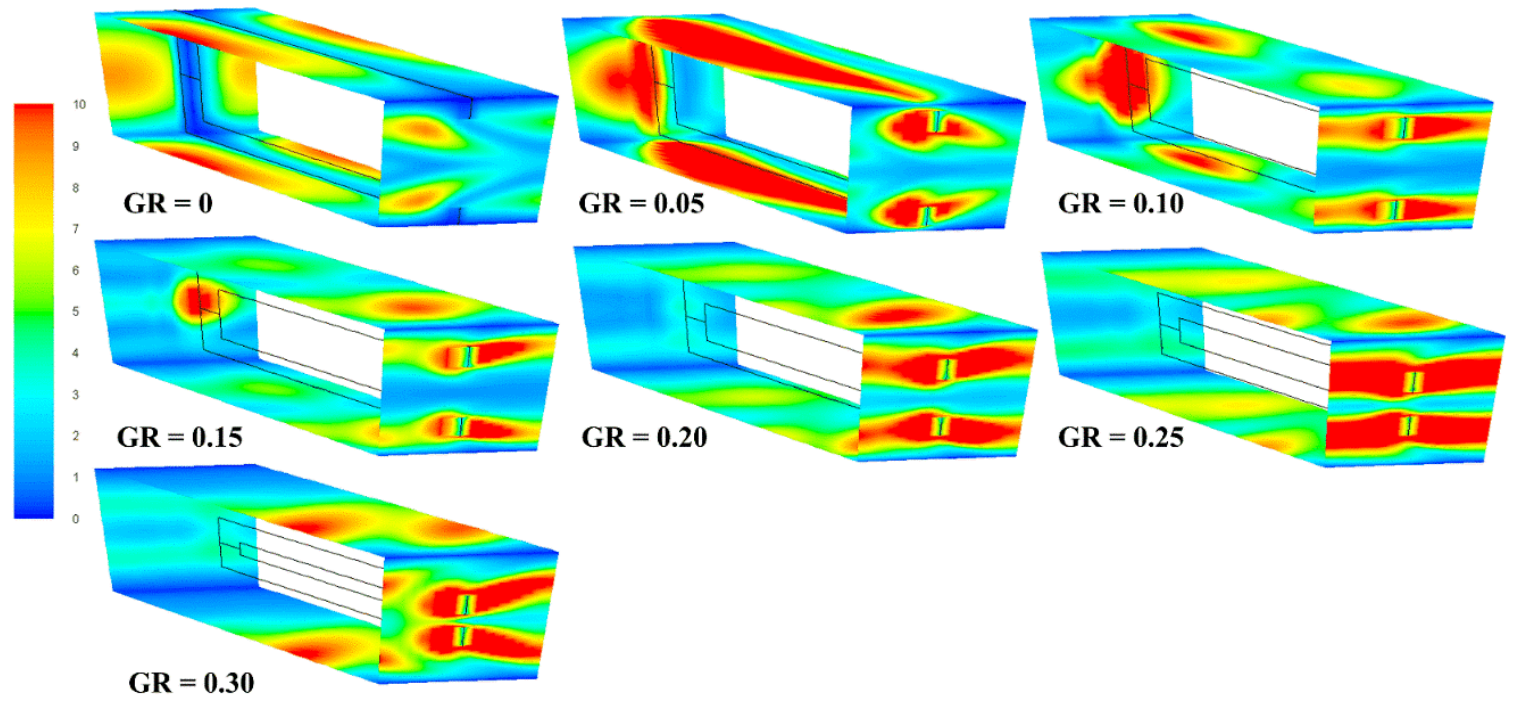

Fig. $12 \mathrm{Nu}_{\mathrm{x}}$ contour for channel inserted with $30^{\circ} \mathrm{C}$-shaped baffle at $\mathrm{BR}=0.15$. 

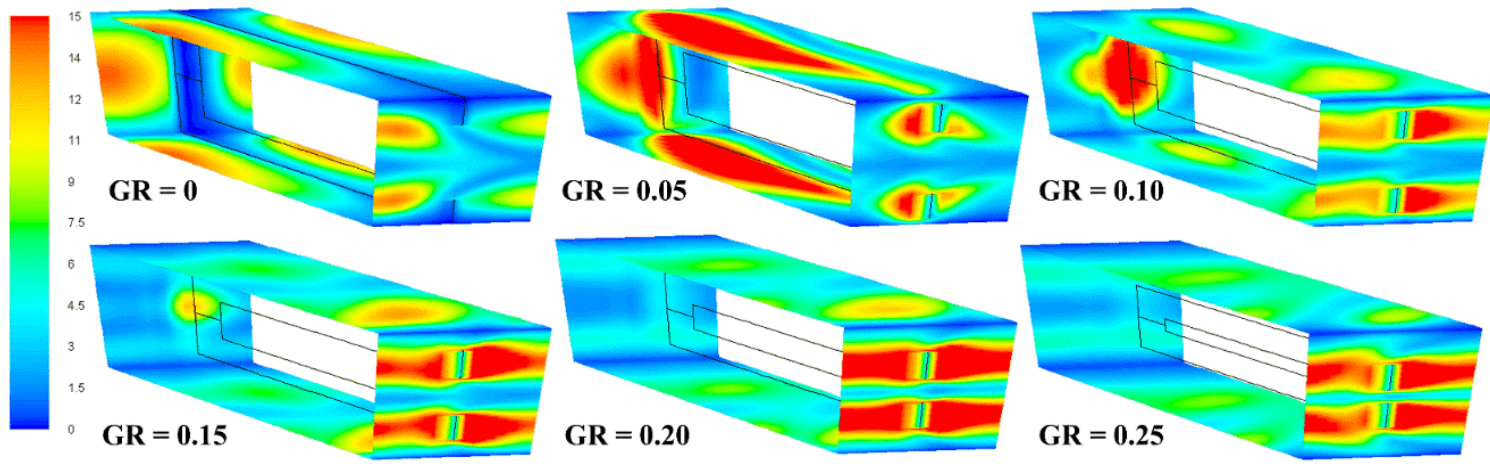

Fig. $13 \mathrm{Nu}_{\mathrm{x}}$ contour for channel inserted with $30^{\circ} \mathrm{C}$-shaped baffle at $\mathrm{BR}=0.20$.
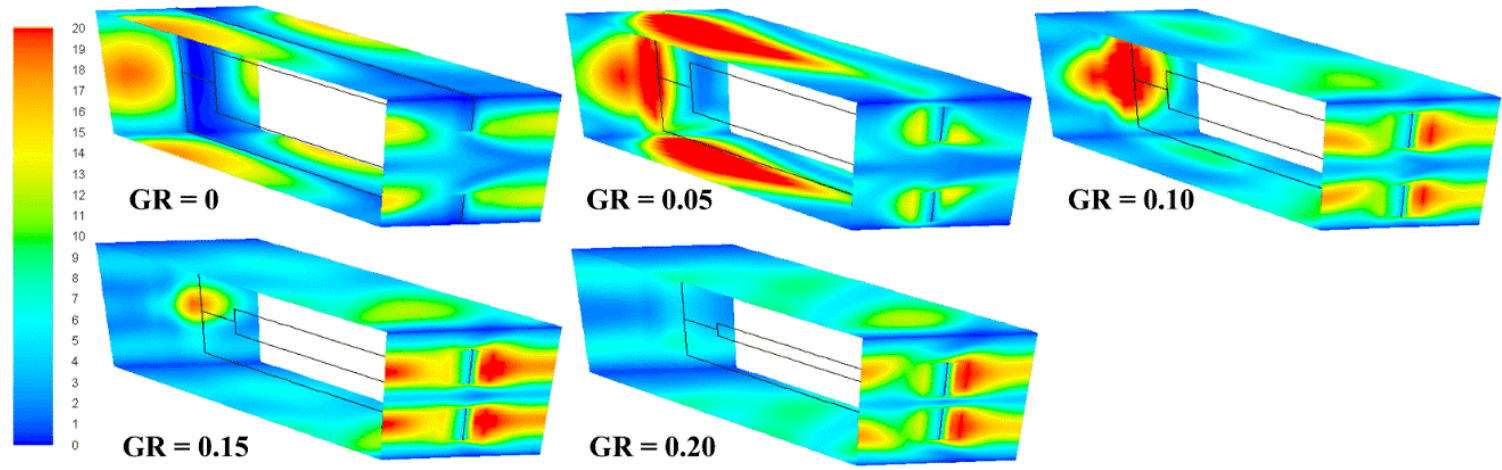

Fig. $14 \mathrm{Nu}_{\mathrm{x}}$ contour for channel inserted with $30^{\circ} \mathrm{C}$-shaped baffle at $\mathrm{BR}=0.25$.
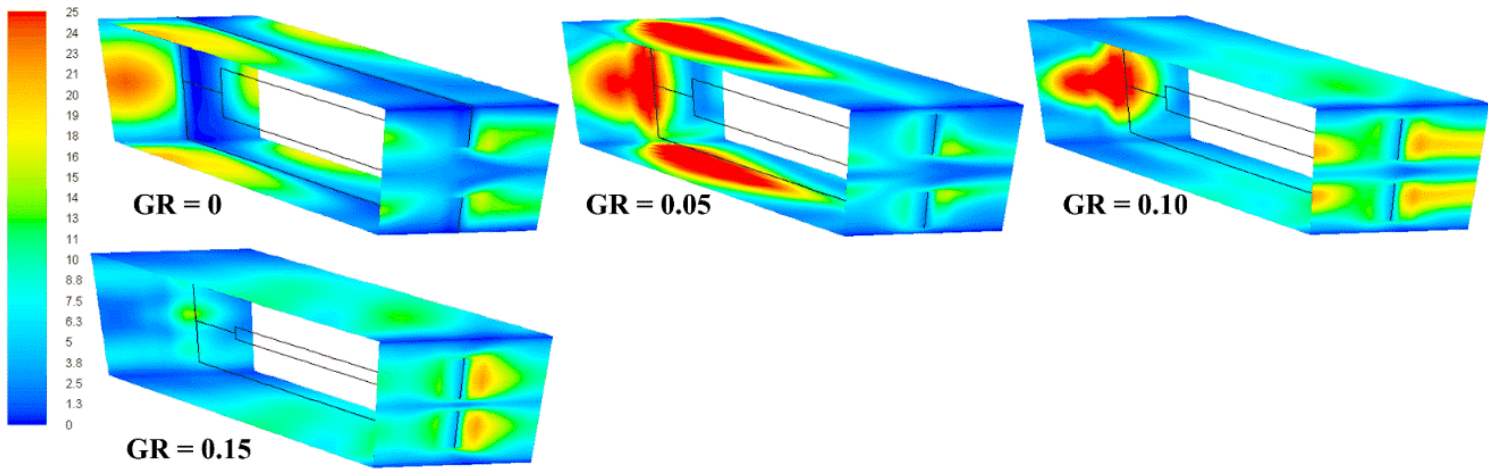

Fig. $15 \mathrm{Nu}_{\mathrm{x}}$ contour for channel inserted with $30^{\circ} \mathrm{C}$-shaped baffle at $\mathrm{BR}=0.30$.

\section{NUMERICAL RESULT AND DISCUSSION}

The numerical results are reported in terms of flow structure and heat transfer characteristics in the heat exchanger square channel inserted with $\mathrm{C}$-shaped baffles. The flow and heat transfer structures can help to describe the mechanisms in the heating system and the change of the boundary layer. The understanding of the mechanisms in the testing section is an important data to support the development of the heat exchanger. The plots of average Nusselt number, friction factor and thermal enhancement factor are also presented.

\subsection{Mechanisms on flow and heat transfer in the tested section}

The streamlines in y-z planes and longitudinal vortex flow are depicted to describe the flow structure in the tested channel. Figs. 6a, b, c, d, e, f and $g$ plot the streamlines in $y-z$ planes of the heat exchanger square channel inserted with $30^{\circ} \mathrm{C}$-shaped baffles at $\mathrm{BR}=0.15$ and $\mathrm{GR}=0$,
$0.05,0.10,0.15,0.20,0.25$ and 0.30 , respectively, and $\mathrm{Re}=600$. The Cshaped baffle in the test section can produce the vortex flow or swirling flow through the square channel. These flow structures will disturb the thermal boundary layer on the heat transfer surface. The thermal boundary layer disturbance is the reason for heat transfer and thermal performance enhancements. The vortex flow also help a better tested fluid mixing in the test section between the cold fluid at the center of the channel and hot fluid near the channel wall. In general, the difference of the $\mathrm{C}$-shaped baffle size effects for the difference of the flow topology in the square channel. The $\mathrm{C}$-shaped baffle with the $\mathrm{GR}=0$ creates the symmetry vortex flow at the upper-lower parts of each plane. The small vortices at the upper-lower right corners are also found in all planes. The C-shaped baffle with the GR $=0.05$ produces the two main symmetry vortex flows at the upper-lower parts of the planes. The four small vortices at the four corners of the square channel are also detected. The small vortices at the center of the plane are found to be larger when increasing GR, while the two main vortex flows are detected in the opposite result. The gap between the $\mathrm{C}$-shaped baffle and the channel 
wall can change the flow configuration in the test section. The number of the vortex flow has change due to some parts of the air flow passes the gap spacing. The increment for the number of the vortex flow helps to a better fluid mixing, but the strength of the vortex flow may decrease. Moreover, the flow direction of the vortex flow reverses when changing the gap value. The change of the flow direction may effect for the change of the peak position for heat transfer rate on the channel wall. This situation will discuss from the local Nusselt number on the heat transfer surface. In conclusion, the optimum gap spacing may bring the augmentations on both heat transfer rate and thermal performance in the heat exchanger square channel.
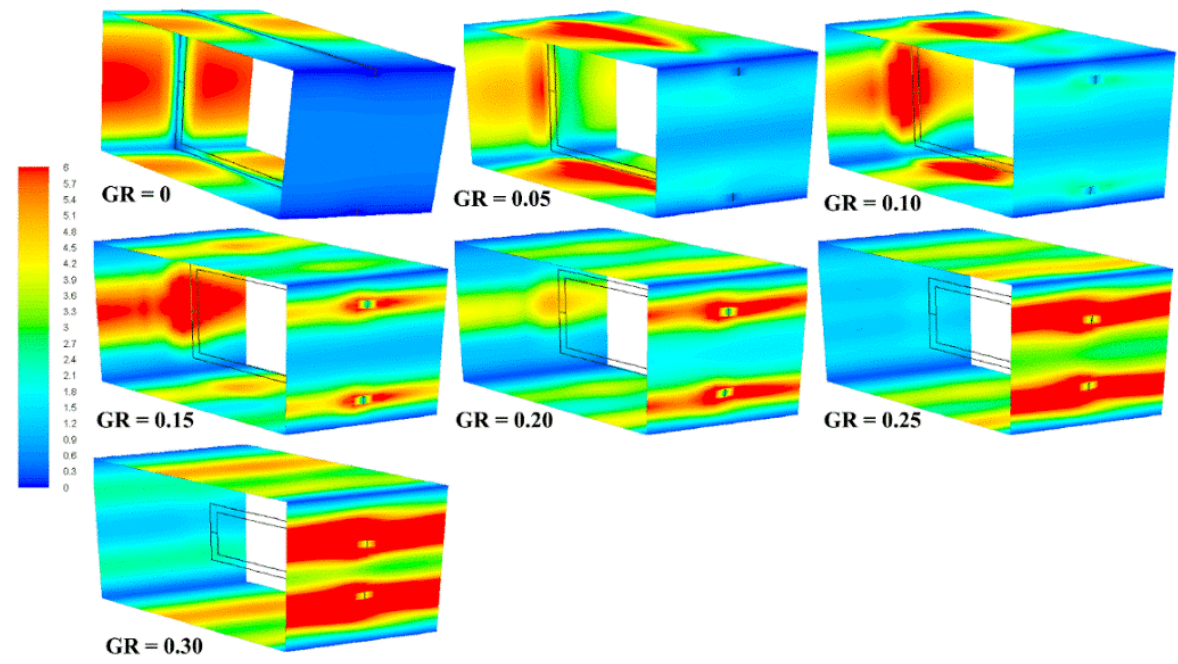

Fig. $16 \mathrm{Nu}_{\mathrm{x}}$ contour for channel inserted with $45^{\circ} \mathrm{C}$-shaped baffle at $\mathrm{BR}=0.05$.
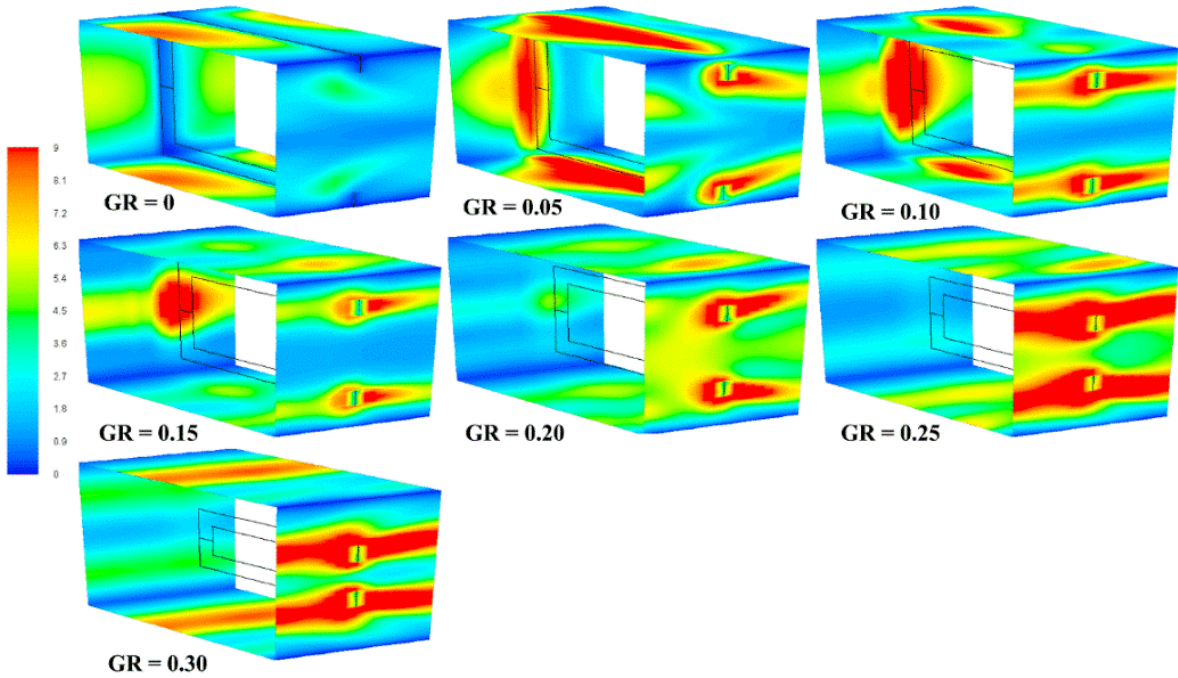

Fig. $17 \mathrm{Nu}_{\mathrm{x}}$ contour for channel inserted with $45^{\circ} \mathrm{C}$-shaped baffle at $\mathrm{BR}=0.10$.
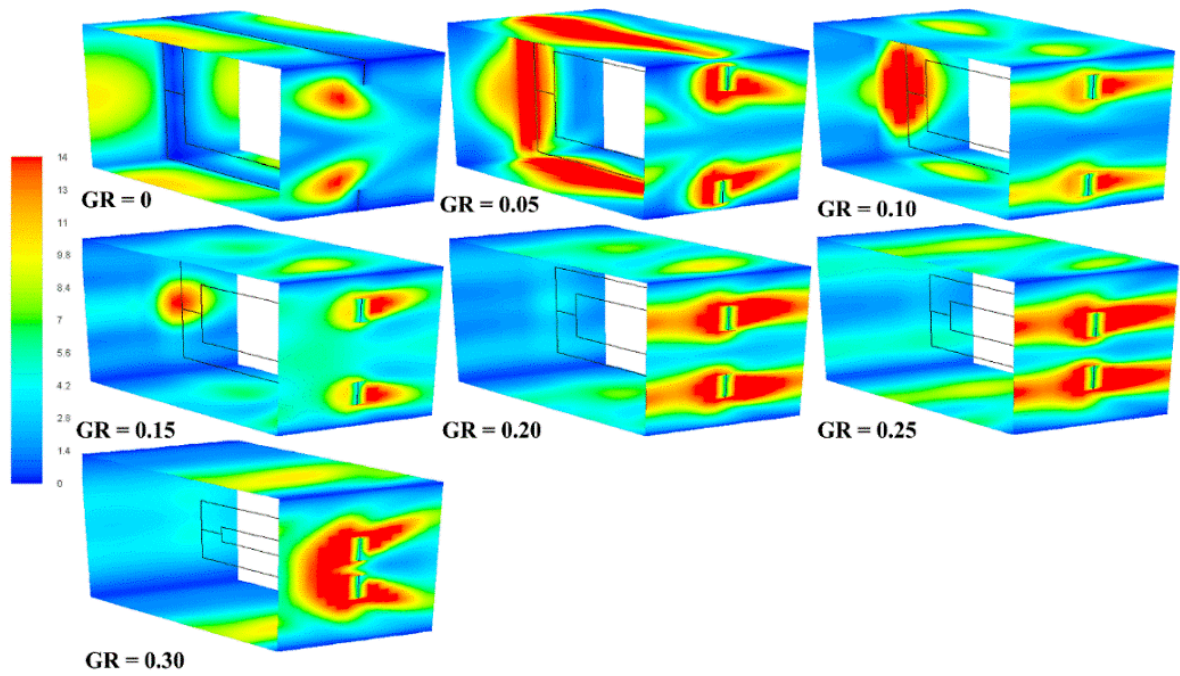

Fig. $18 \mathrm{Nu}_{\mathrm{x}}$ contour for channel inserted with $45^{\circ} \mathrm{C}$-shaped baffle at $\mathrm{BR}=0.15$. 

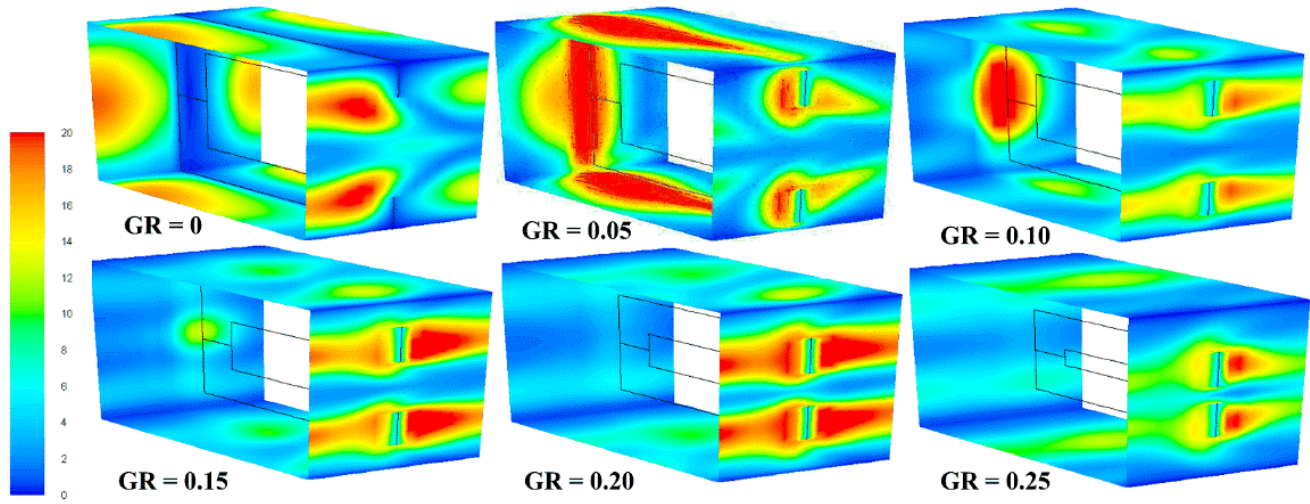

Fig. $19 \mathrm{Nu}_{\mathrm{x}}$ contour for channel inserted with $45^{\circ} \mathrm{C}$-shaped baffle at $\mathrm{BR}=0.20$.
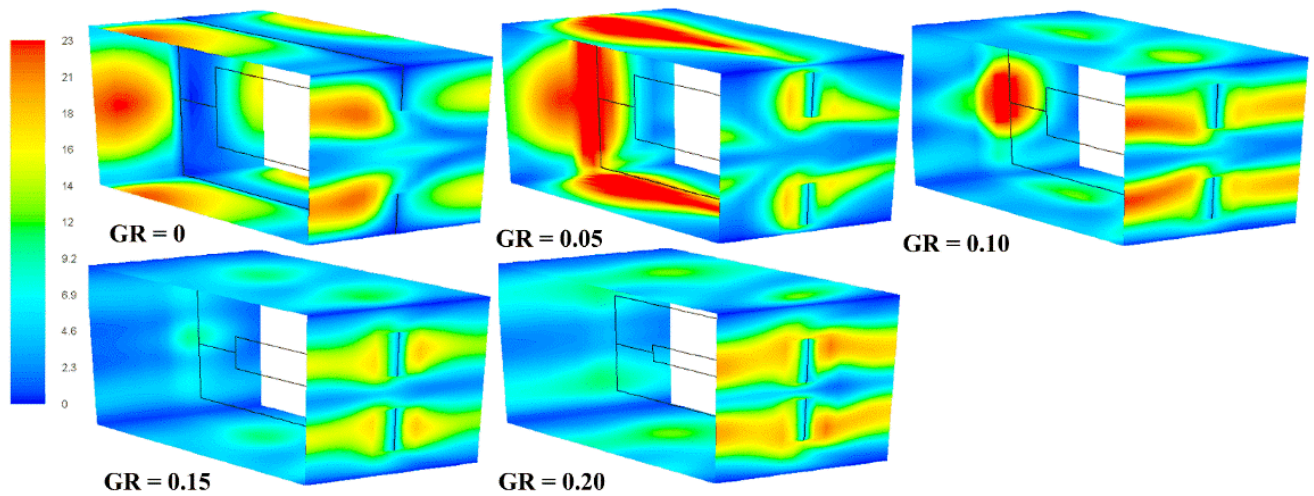

$\mathbf{G R}=\mathbf{0 . 1 0}$

Fig. $20 \mathrm{Nu}_{\mathrm{x}}$ contour for channel inserted with $45^{\circ} \mathrm{C}$-shaped baffle at $\mathrm{BR}=0.25$.
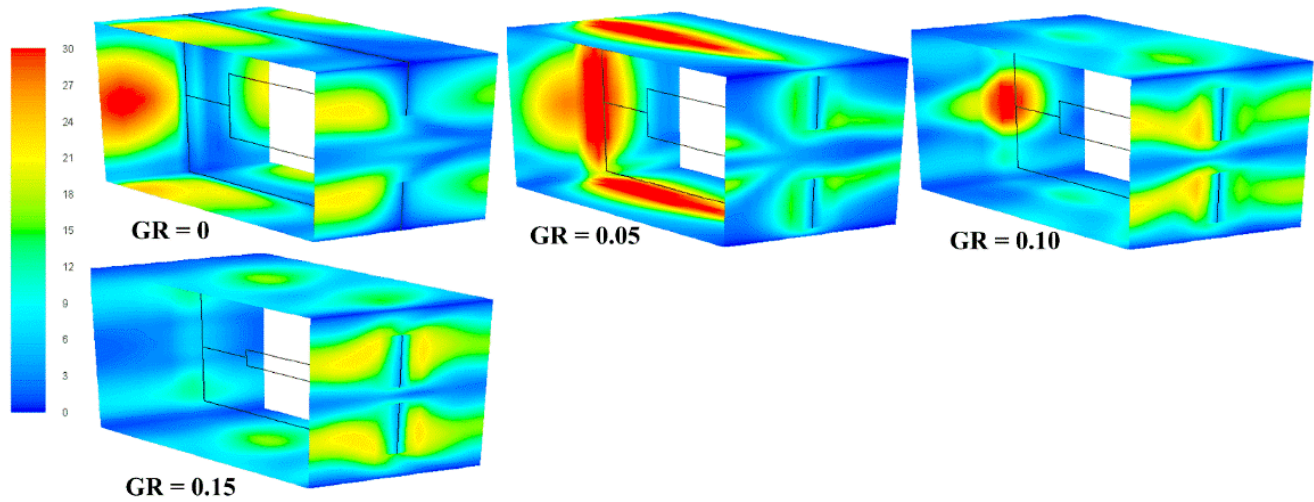

Fig. $21 \mathrm{Nu}_{\mathrm{x}}$ contour for channel inserted with $45^{\circ} \mathrm{C}$-shaped baffle at $\mathrm{BR}=0.30$.

The longitudinal vortex flow impinging on the sidewall and lower wall in the heat exchanger square channel fitted with $45^{\circ} \mathrm{C}$-shaped baffle are illustrated as Figs. 7a and b, respectively, for $\mathrm{BR}=0.15, \mathrm{GR}=0$ and $\mathrm{Re}$ $=800$. The longitudinal vortex flow is an indicator to help to explain the impinging of the vortex flow on the heat exchanger walls and thermal boundary layer disruption. As the figure, the bounce of the vortex flow is clearly detected at the lower wall and sidewall of the square channel heat exchanger. The impinging flow on the heat transfer surface directly improves the heat transfer rate and thermal efficiency and helps a better fluid mixing in the test section. Fig. 8 plots the longitudinal vortex flow of the heat exchanger square channel fitted with $45^{\circ} \mathrm{C}$-shaped baffle at $\mathrm{BR}=0.15, \mathrm{GR}=0.15$ and $\mathrm{Re}=800$. Considering at the figure, some parts of the tested fluid flow passes the lower gap spacing. This behavior helps a better fluid mixing and also changes the flow structure, but the main vortex strength may decreases.

To check the change of the thermal boundary layer on the channel walls, the temperature distribution in $y-z$ planes is plotted. The temperature contour also describes the fusion of the tested fluid in the test section. Figs. 9a, b, c, d, e, f and g show the temperature distribution in transverse planes of the square channel heat exchanger placed with $30^{\circ}$ C-shaped baffle at $\mathrm{BR}=0.15, \mathrm{Re}=800$ for $\mathrm{GR}=0,0.05,0.10,0.15$, $0.20,0.25$ and 0.30 , respectively. Generally, the red layer of the hot fluid is found near the channel wall, while the blue contour of the cold fluid is detected at the center of the square channel. When inserting the $\mathrm{C}$-shaped baffle in the test section, the contour of the temperature has change. The red layer seems to be thinner, while the blue contour distributes from the 
center of the square channel. The modification of the red layer is the thermal boundary layer reformation on the heat transfer surface. The position and thickness of the thermal boundary layer reformation are differently found when modifying the gap spacing value.

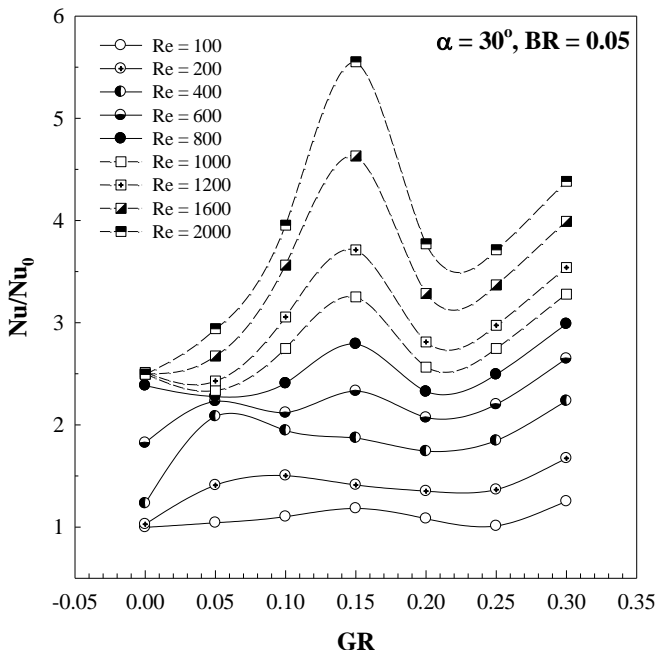

(a)

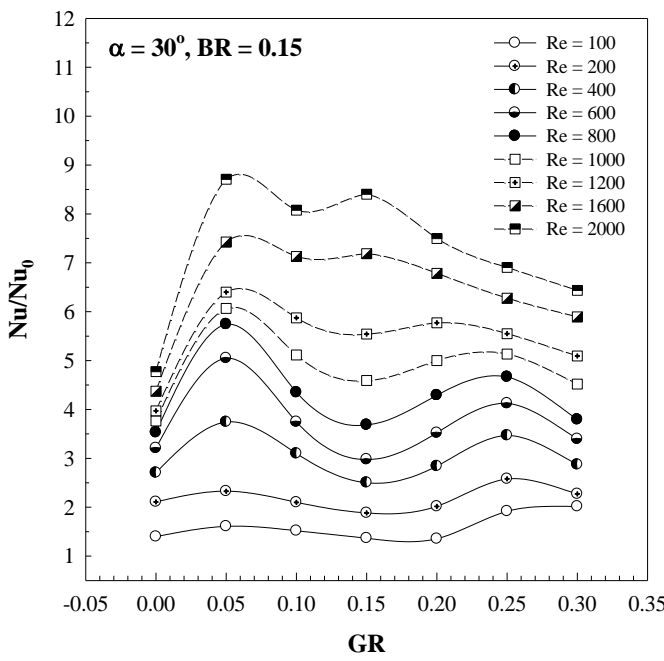

(c)

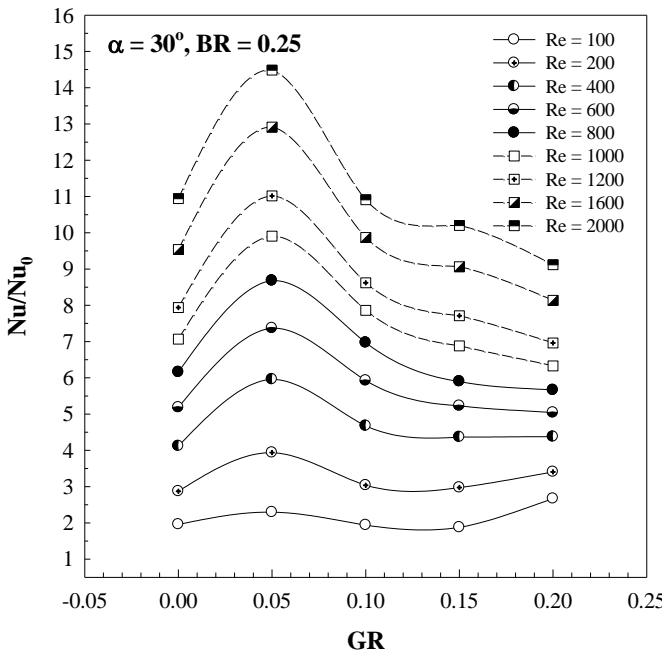

(e)

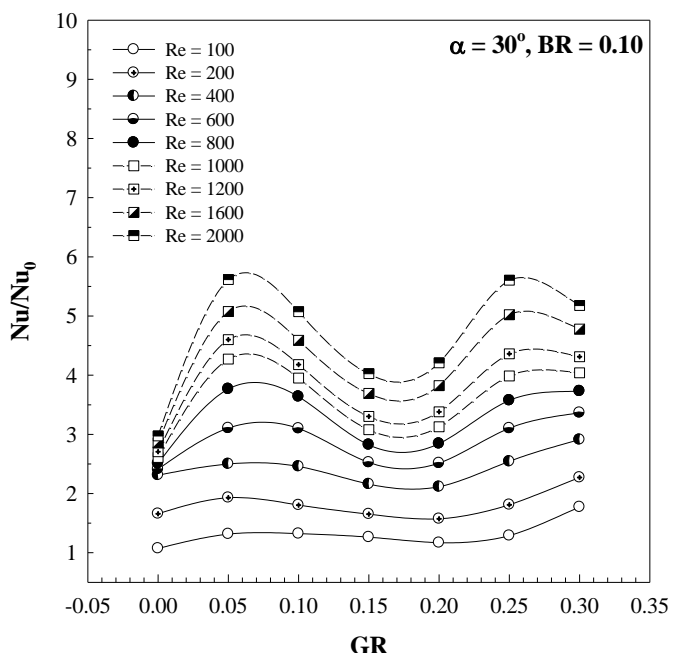

(b)

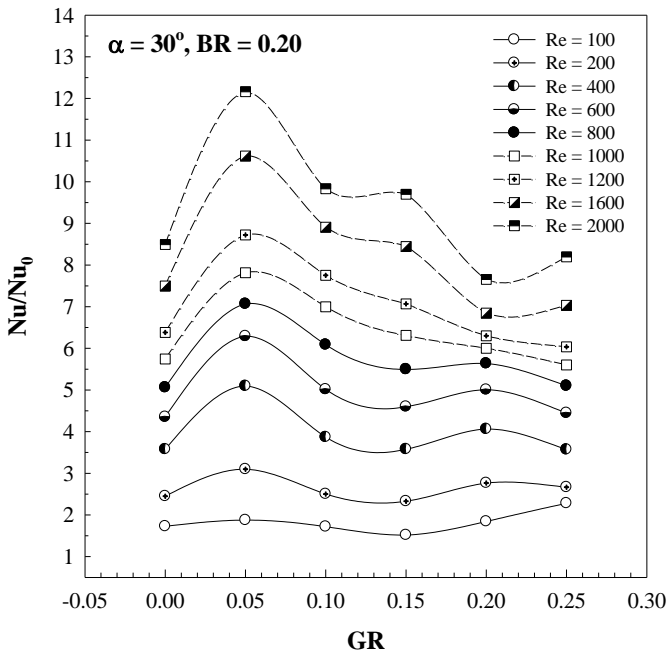

(d)

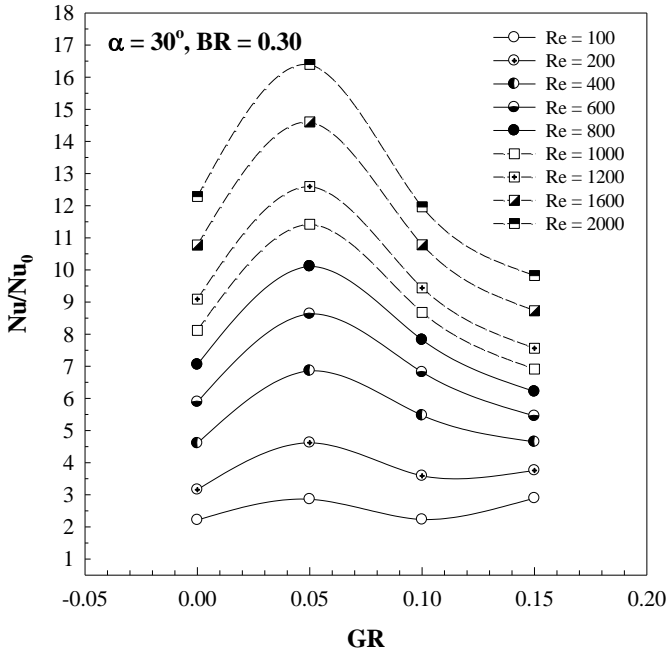

(f)

Fig. $22 \mathrm{Nu} / \mathrm{Nu}_{0}$ vs $\mathrm{GR}$ for (a) $\mathrm{BR}=0.05$, (b) $\mathrm{BR}=0.10$, (c) $\mathrm{BR}=0.15$, (d) $\mathrm{BR}=0.20$, (e) $\mathrm{BR}=0.25$ and (f) $\mathrm{BR}=0.30$ at $\alpha=30^{\circ}$. 


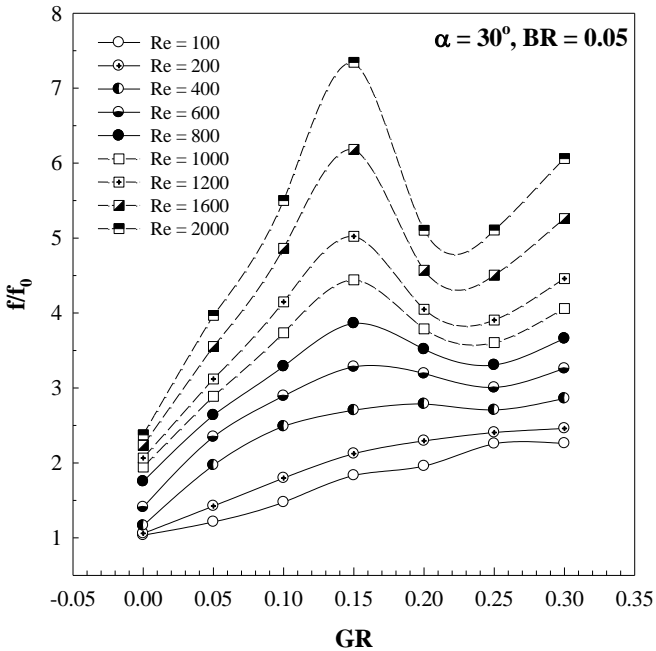

(a)

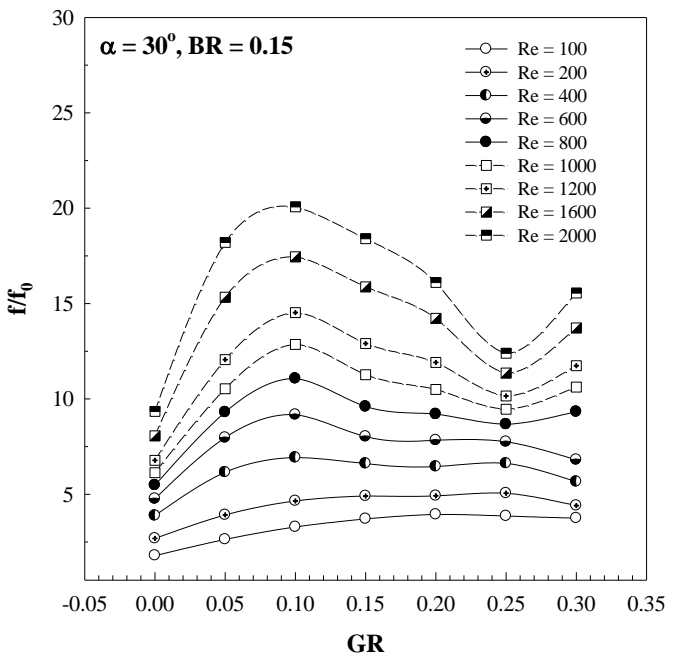

(c)

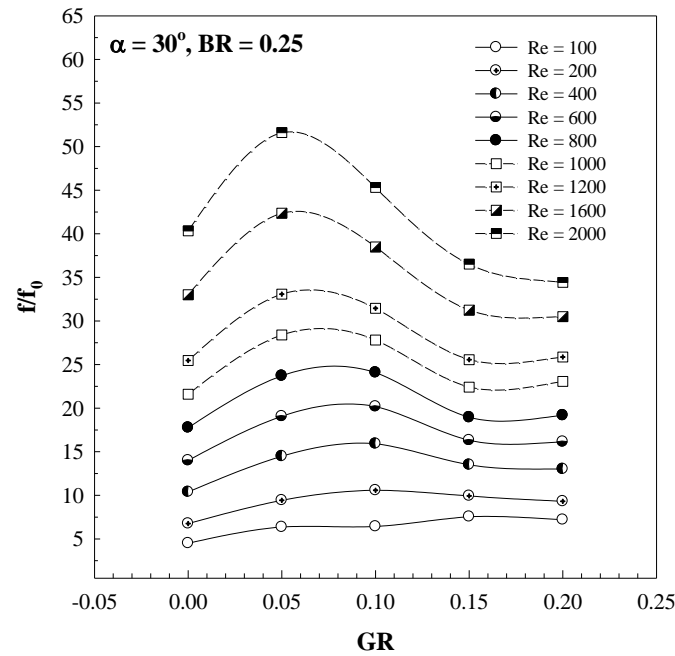

(e)

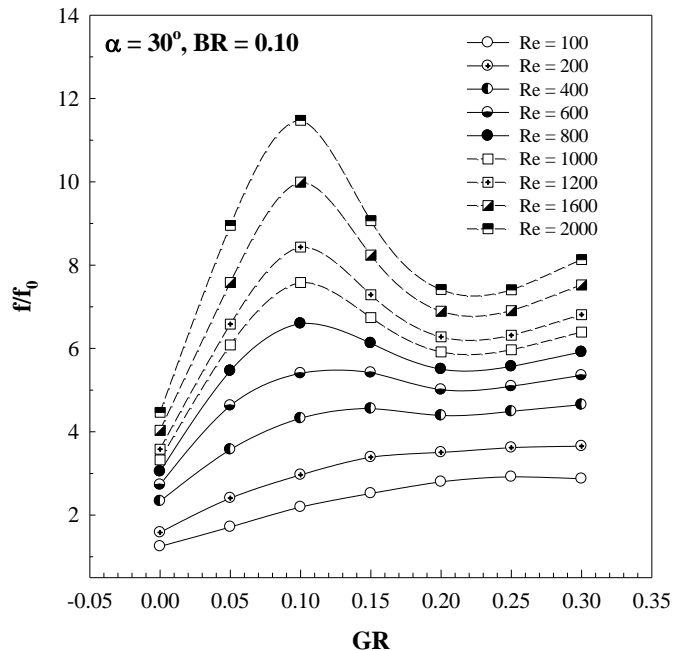

(b)

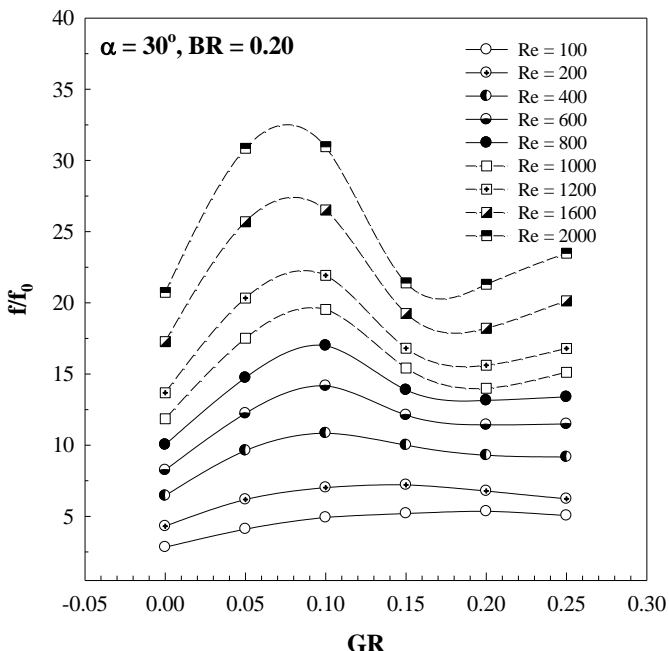

(d)

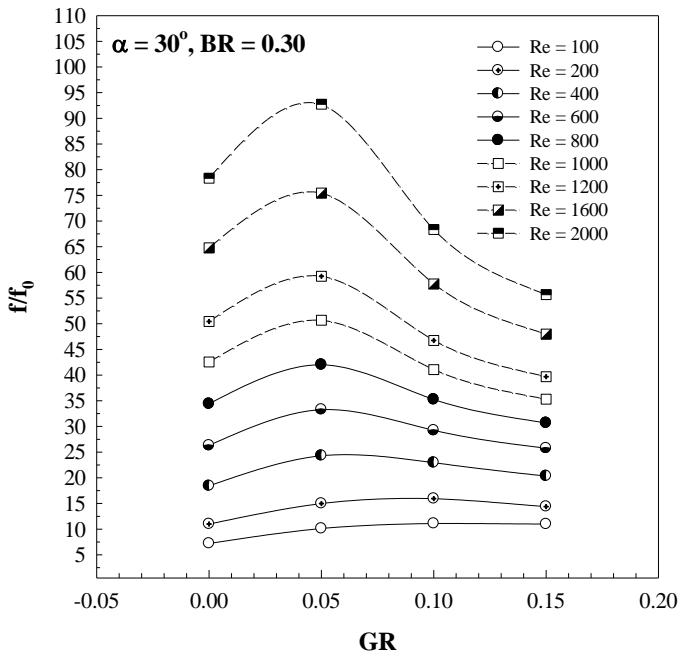

(f)

Fig. $23 \mathrm{f} / \mathrm{f}_{0}$ vs $\mathrm{GR}$ for (a) $\mathrm{BR}=0.05$, (b) $\mathrm{BR}=0.10$, (c) $\mathrm{BR}=0.15$, (d) $\mathrm{BR}=0.20$, (e) $\mathrm{BR}=0.25$ and (f) $\mathrm{BR}=0.30$ at $\alpha=30^{\circ}$. 


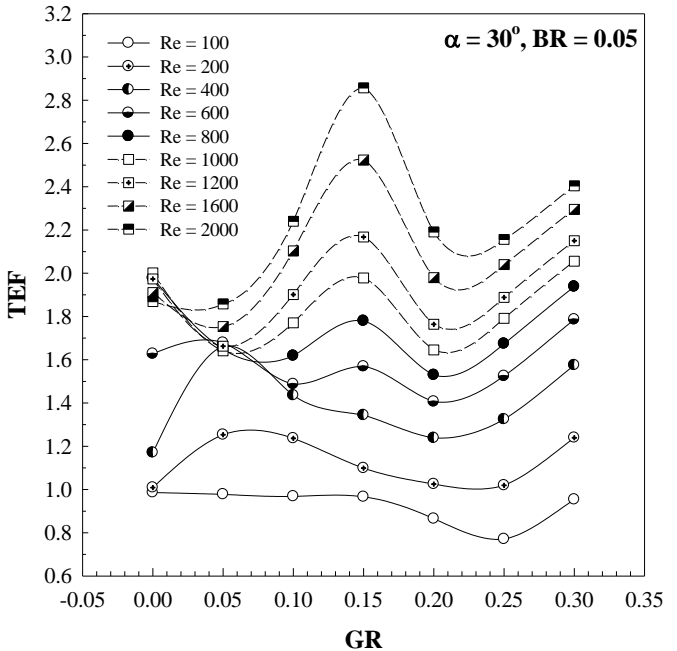

(a)

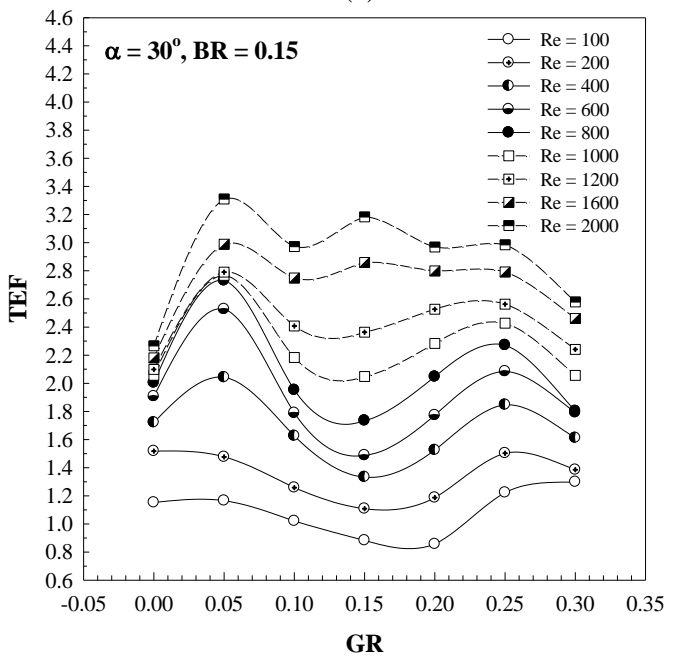

(c)

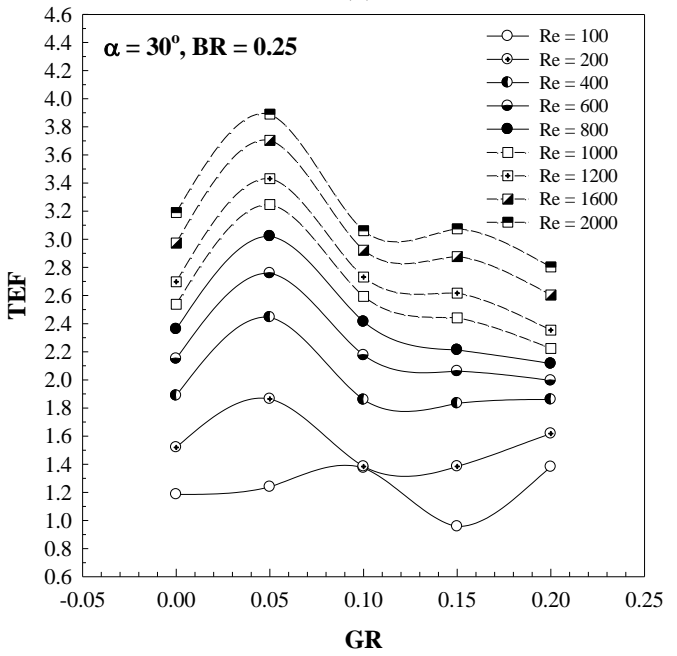

(e)

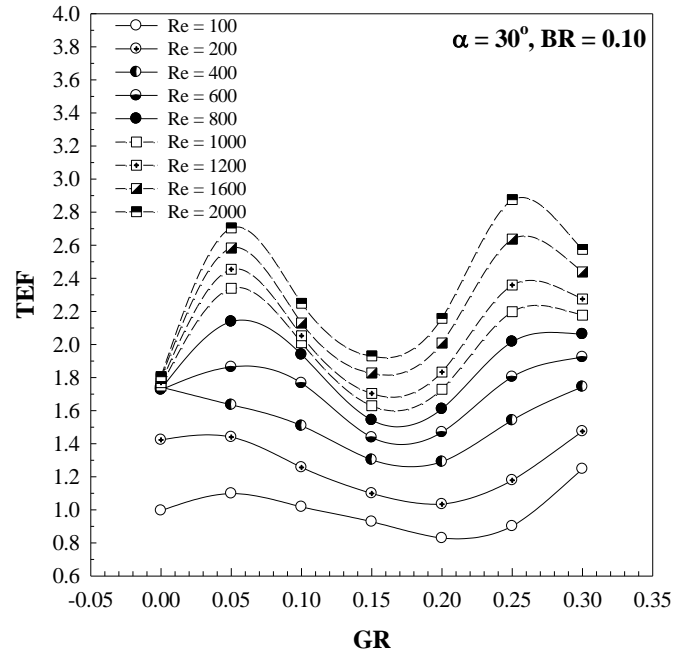

(b)

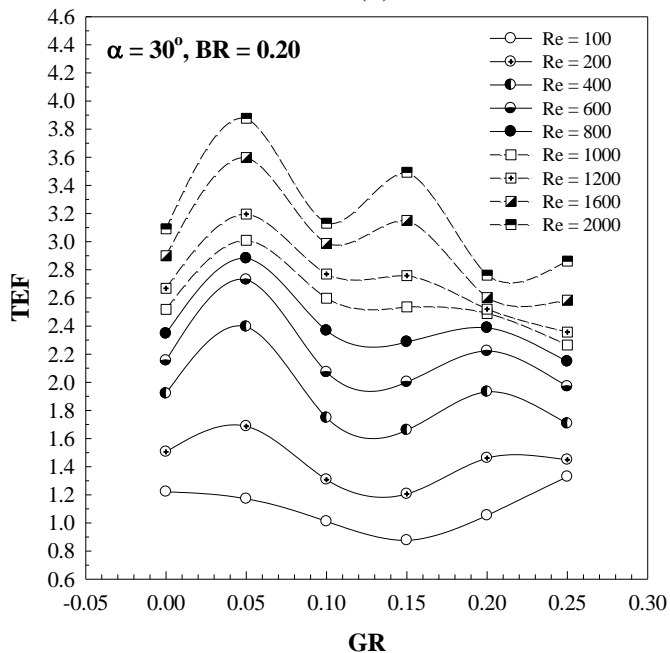

(d)

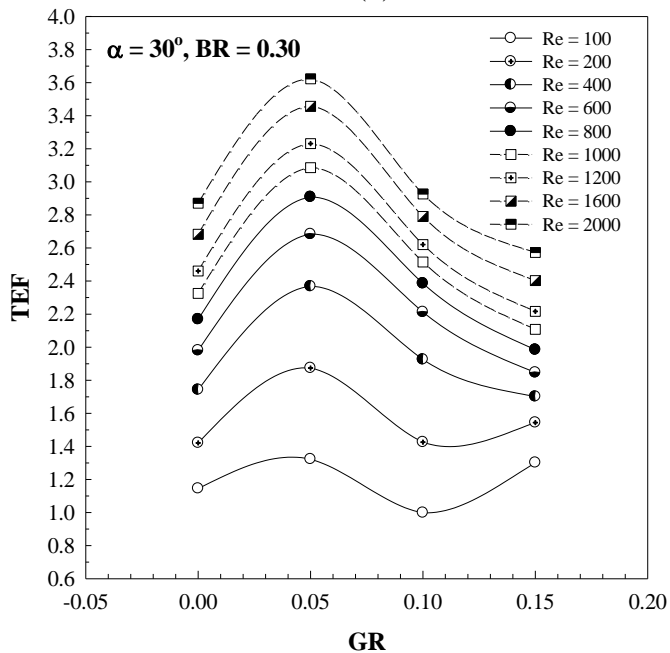

(f)

Fig. 24 TEF vs GR for (a) $B R=0.05$, (b) $B R=0.10$, (c) $B R=0.15$, (d) $B R=0.20$, (e) $B R=0.25$ and (f) $B R=0.30$ at $\alpha=30^{\circ}$. 

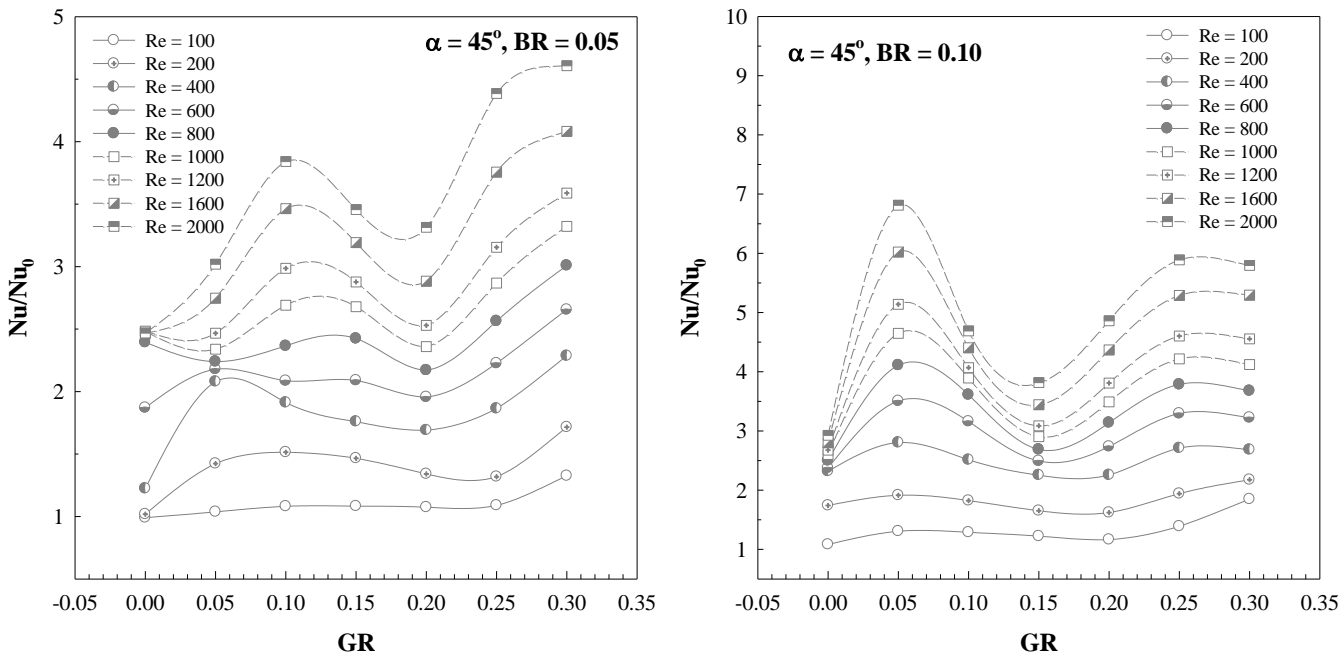

(a)
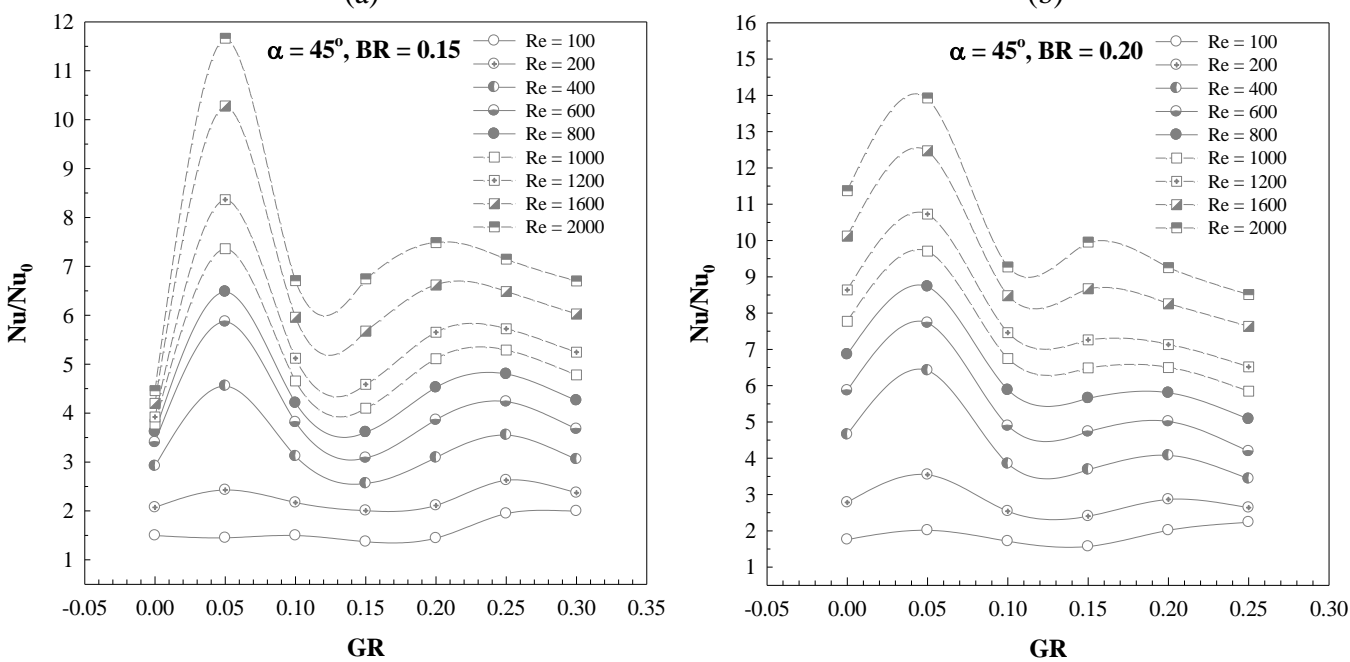

(c)

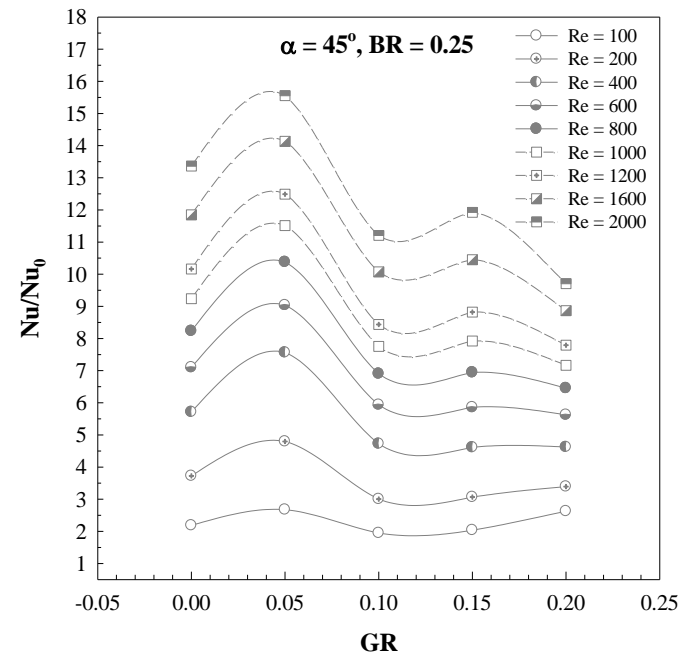

(d)

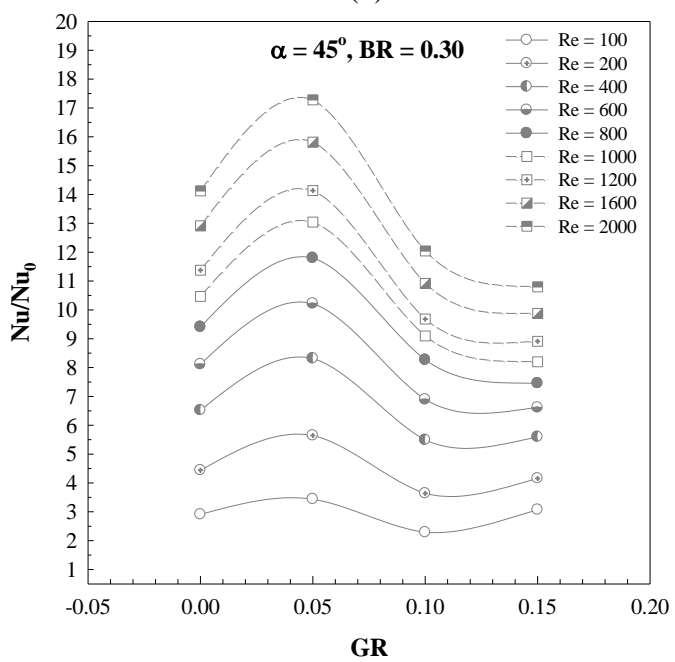

(e)

(f)

Fig. $25 \mathrm{Nu} / \mathrm{Nu}_{0}$ vs $\mathrm{GR}$ for (a) $\mathrm{BR}=0.05$, (b) $\mathrm{BR}=0.10$, (c) $\mathrm{BR}=0.15$, (d) $\mathrm{BR}=0.20$, (e) $\mathrm{BR}=0.25$ and (f) $\mathrm{BR}=0.30$ at $\alpha=45^{\circ}$. 

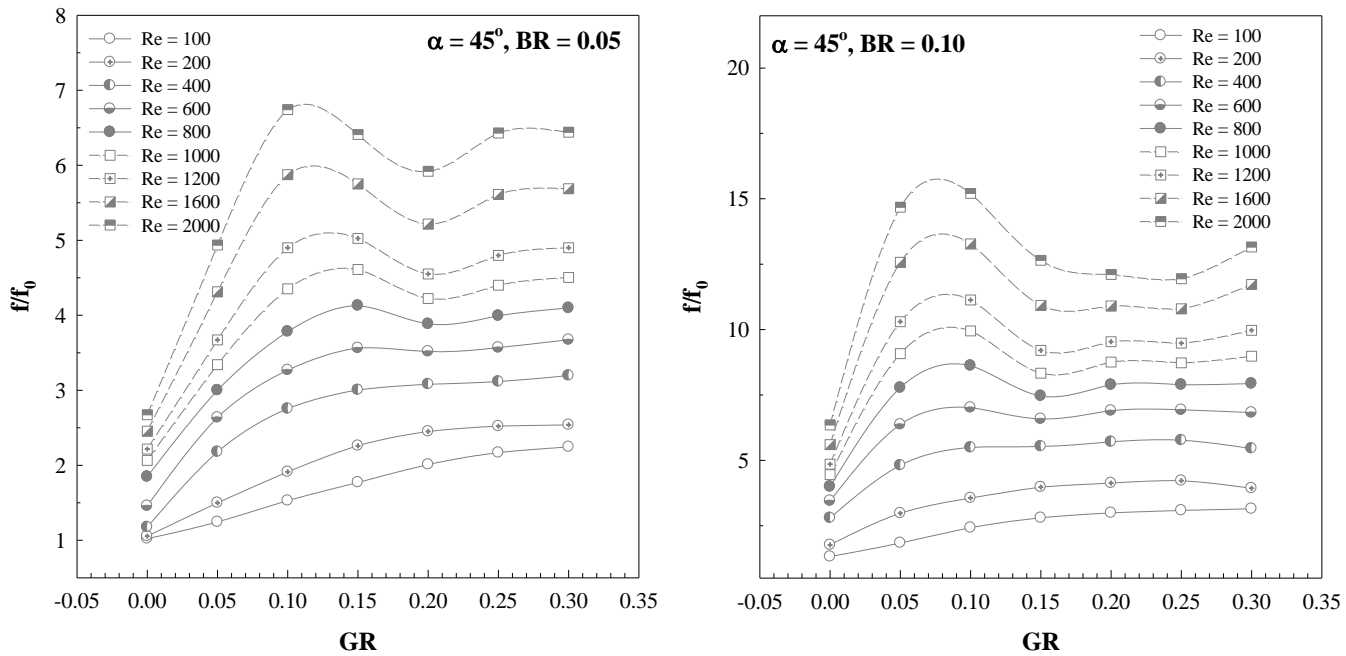

(a)

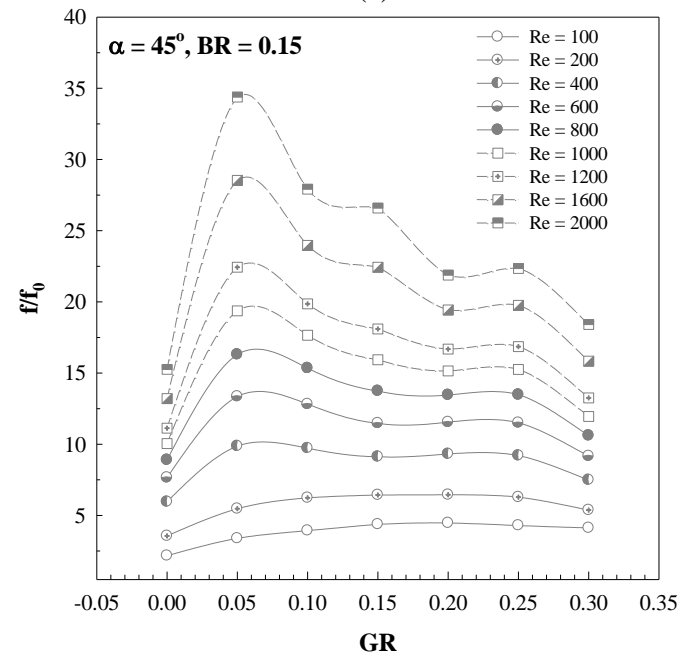

(b)

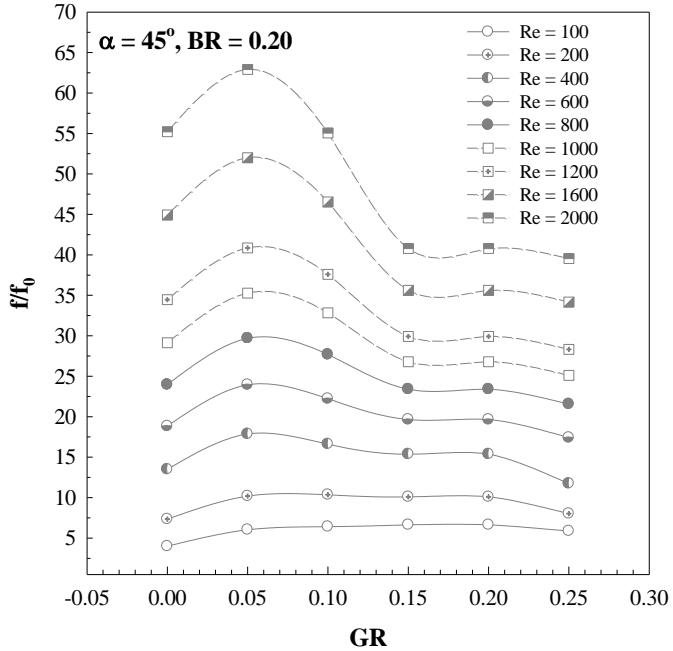

(c)

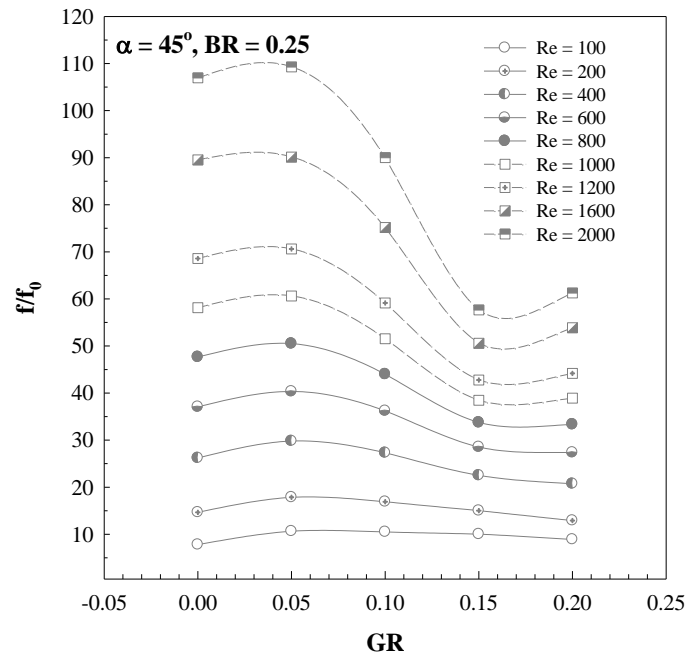

(d)

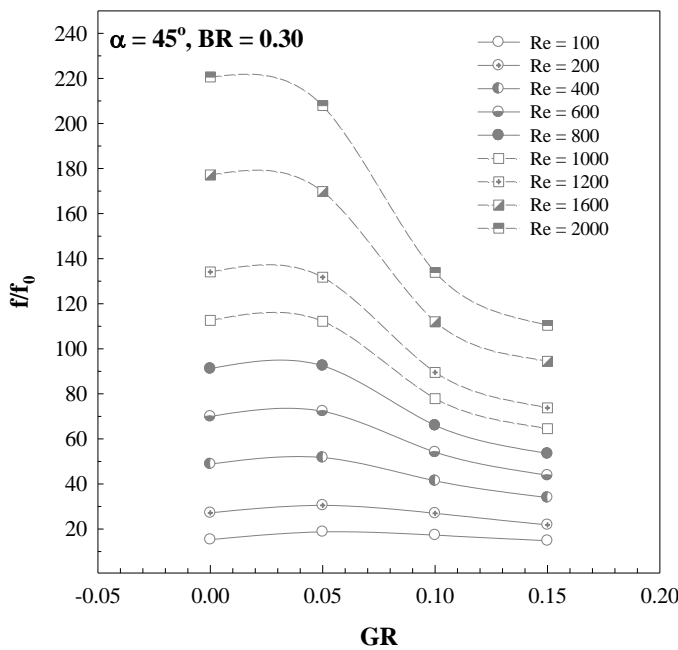

(e)

(f)

Fig. $26 \mathrm{f} / \mathrm{f}_{0}$ vs $\mathrm{GR}$ for (a) $\mathrm{BR}=0.05$, (b) $\mathrm{BR}=0.10$, (c) $\mathrm{BR}=0.15$, (d) $\mathrm{BR}=0.20$, (e) $\mathrm{BR}=0.25$ and (f) $\mathrm{BR}=0.30$ at $\alpha=45^{\circ}$. 


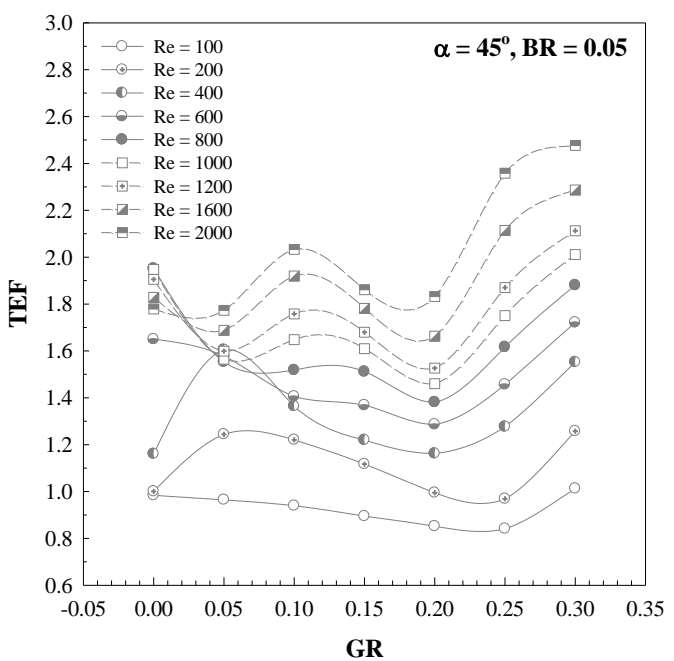

(a)

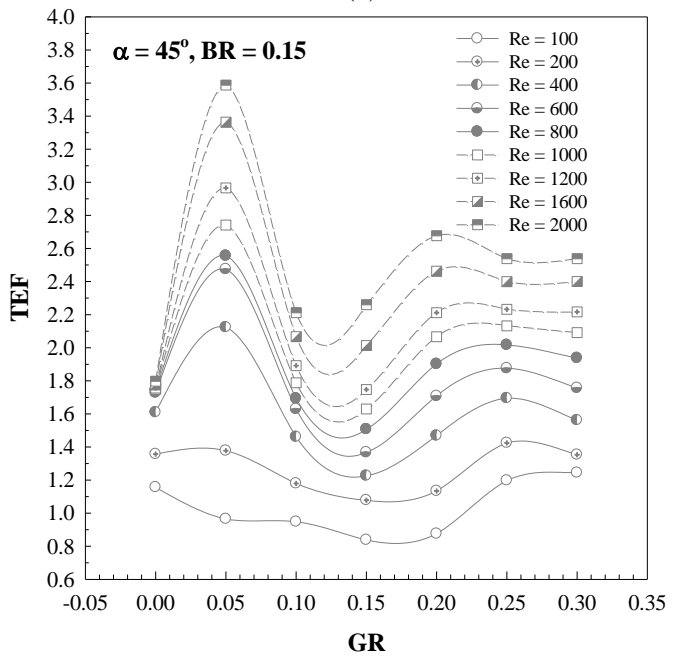

(c)

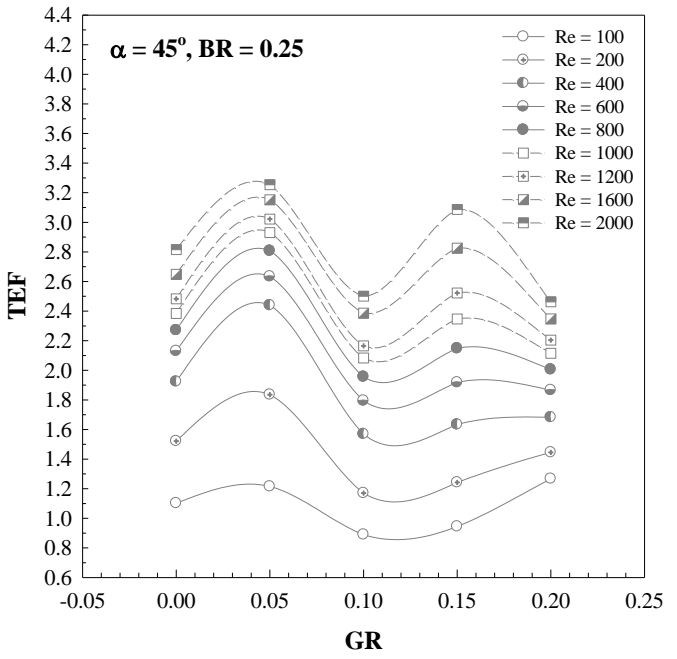

(e)

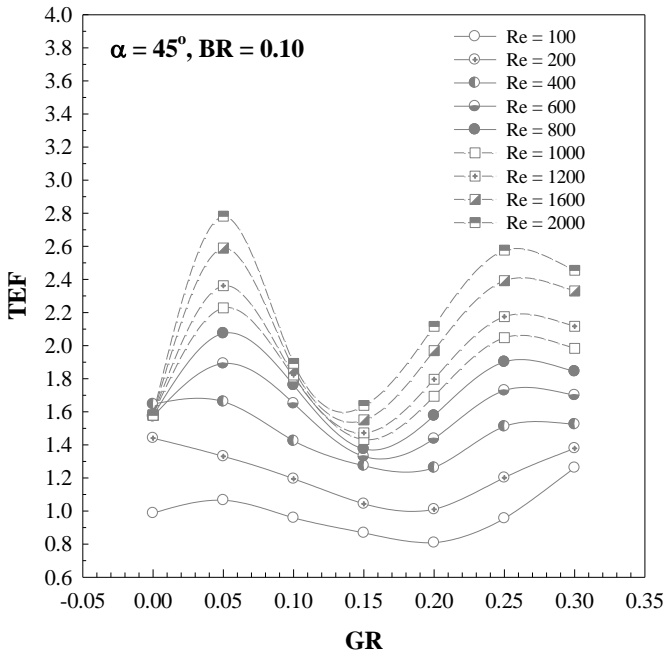

(b)

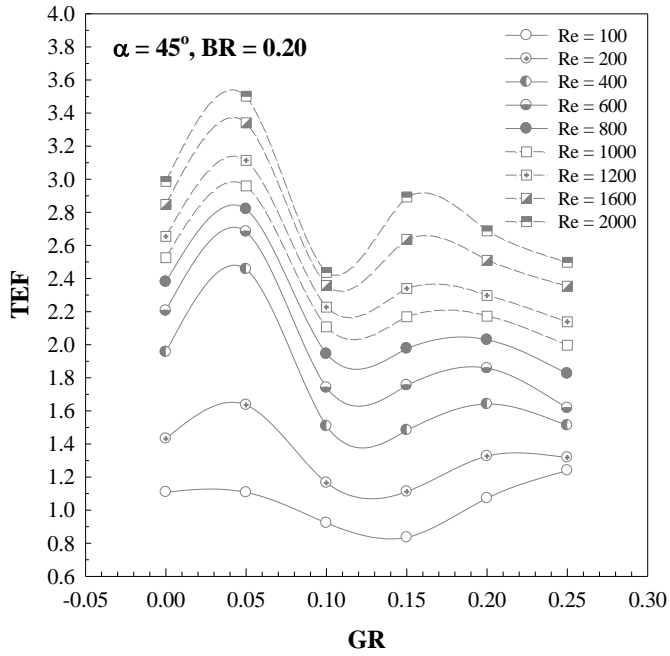

(d)

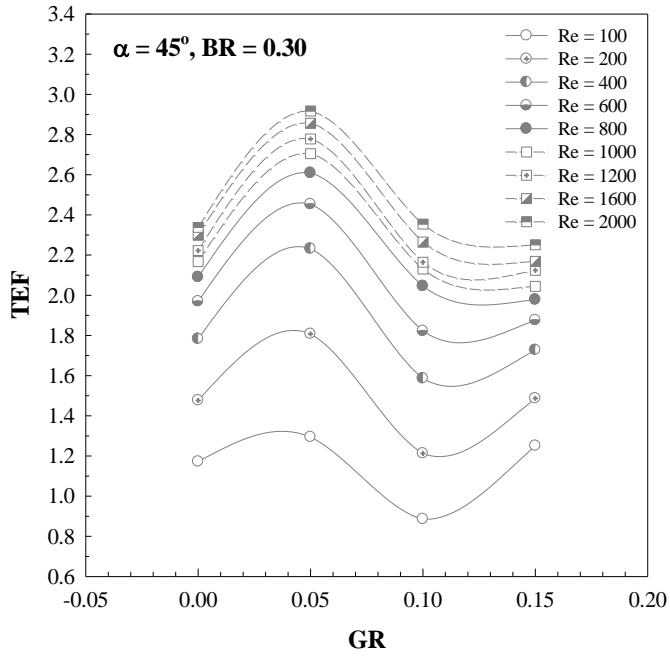

(f)

Fig. 27 TEF vs GR for (a) $B R=0.05$, (b) $B R=0.10$, (c) $B R=0.15$, (d) $B R=0.20$, (e) $B R=0.25$ and (f) $B R=0.30$ at $\alpha=45^{\circ}$.

The local Nusselt number on the square channel walls placed with Cshaped baffle at various BR, GR and flow attack angles are presented as Figs. 10 to 21 . The local Nusselt number distribution is the best indicator to check the variation of the heat transfer surface on the channel walls of the heat exchanger.
For $\mathrm{BR}=0.05, \alpha=30^{\circ}$ and $\mathrm{GR}=0$, the peak of heat transfer regime is clearly found at the left sidewall of the channel, while the poor heat transfer region is detected at the right sidewall of the channel. In the range $0.05 \leq \mathrm{GR} \leq 0.10$, the red contour for the local Nusselt number of the left sidewall decreases, but increases for the upper-lower walls. The heat transfer rate of the right sidewall is enhancing when augmenting the GR 
values. It is clearly seen in the figure that the highest heat transfer regime appears at the right sidewall of the square channel for the $\mathrm{GR}=0.30$. The similar pattern of the heat transfer behavior is found in all $\mathrm{BR}, \alpha$ and $\mathrm{Re}$ values.

\subsection{Thermal efficiency analysis}

The thermal performance analysis in the square channel heat exchanger placed with various parameters of the C-shaped baffle are plotted in terms of relations of the Nusselt number ratio $\left(\mathrm{Nu} / \mathrm{Nu}_{0}\right)$, friction factor ratio ( $\left.f / f_{0}\right)$ and thermal enhance factor (TEF) with gap spacing ratio. In general, the heat transfer rate and pressure loss in the test section increase when augmenting the Reynolds number for all investigated cases. The insertion of the $\mathrm{C}$-shaped baffle in the heat exchanger system brings higher heat transfer rate than the smooth square channel $\left(\mathrm{Nu} / \mathrm{Nu}_{0}>1\right)$ due to the creation of the vortex flow, swirling flow, longitudinal vortex flow and the change of the thermal boundary layer. However, the pressure loss in the test section also increases greater than the smooth square channel $\left(f / f_{0}>1\right)$ when fitted the $C$-shaped baffle in the test section, especially, at high Re and BR values.

The variations of the $\mathrm{Nu} / \mathrm{Nu}_{0}$ with $\mathrm{GR}$ for $\mathrm{BR}=0.05,0.10,0.15$, $0.20,0.25$ and 0.30 are created as Figs. 22a, b, c, d, e and f, respectively, at $\alpha=30^{\circ}$. The peak of heat transfer rate is detected at GR $=0.15$ for BR $=0.05$. At $\mathrm{BR}=0.10$, the $\mathrm{GR}=0.05$ and 0.25 give the highest heat transfer rate. The highest heat transfer rate for $\mathrm{BR}=0.15-0.30$ is found at gap spacing around $5 \%$. The $\mathrm{f} / \mathrm{f}_{0}$ versus GR is depicted as Figs. $23 \mathrm{a}, \mathrm{b}$, $\mathrm{c}, \mathrm{d}$, e and $\mathrm{f}$, respectively, for $\mathrm{BR}=0.05,0.10,0.15,0.20,0.25$ and 0.30 , respectively, at $\alpha=30^{\circ}$. The peak of the pressure loss is detected at gap spacing around $15,10,10,10,5$ and $5 \%$, respectively, at $\mathrm{BR}=0.05,0.10$, $0.15,0.20,0.25$ and 0.30 . The plots of TEF with GR are presented as Figs. $24 \mathrm{a}, \mathrm{b}, \mathrm{c}, \mathrm{d}$, e and $\mathrm{f}$ for $\mathrm{BR}=0.05,0.10,0.15,0.20,0.25$ and 0.30, respectively, at $\alpha=30^{\circ}$. The optimum TEF is found at GR $=0.15,0.25$, $0.05,0.05,0.05$ and 0.05 for $\mathrm{BR}=0.05,0.10,0.15,0.20,0.25$ and 0.30 , respectively.

For the $30^{\circ} \mathrm{C}$-shaped baffle with $\mathrm{BR}=0.05$, the heat transfer rate, friction loss are around $1.00-5.50$ and $1.00-7.40$ times above the smooth channel, respectively. The maximum TEF of the $\mathrm{BR}=0.05$ and $\alpha=30^{\circ}$ is around 2.89 . The $30^{\circ} \mathrm{C}$-shaped baffle with the $\mathrm{BR}=0.10$ gives the $\mathrm{Nu} / \mathrm{Nu}_{0}$ and $\mathrm{f} / \mathrm{f}_{0}$ around $1.00-5.50$ and $1.00-11.60$, respectively, while the optimum TEF is around 2.90. The heat transfer, friction loss around $1.30-8.80$ and $1.90-20.00$ times higher than the smooth channel with the maximum TEF around 3.30 are found at $\mathrm{BR}=0.15$ and $\alpha=30^{\circ}$. The $\mathrm{BR}=0.20$ and $\alpha=30^{\circ}$ performs the heat transfer rate and pressure loss around $1.50-12.40$ and $2.90-31.00$ greater than the plain channel, respectively, with the peak of TEF around 3.85. The $\mathrm{Nu} / \mathrm{Nu}_{0}$ of $\mathrm{BR}=$ 0.25 and 0.30 is around $1.80-14.50$ and $2.10-16.50$, respectively, while the $\mathrm{f} / \mathrm{f}_{0}$ is around $2.50-53.00$ and $8.00-94.00$, respectively, at $\alpha=30^{\circ}$. The peak of thermal performance enhancement is around 3.90 at $\mathrm{BR}=$ 0.25 , while around 3.60 at $\mathrm{BR}=0.30$ and $\alpha=30^{\circ}$.

Figs. 25a, b, c, d, e and f report the relations of $\mathrm{Nu} / \mathrm{Nu}_{0}$ with $\mathrm{GR}$ for $\mathrm{BR}=0.05,0.10,0.15,0.20,0.25$ and 0.30 , respectively, at $\alpha=45^{\circ}$. The plots of TEF with GR at BR $=0.05,0.10,0.15,0.20,0.25$ and 0.30 for $\alpha$ $=45^{\circ}$ are showed as Figs. 27a, b, c, d, e and f, respectively. The maximum heat transfer rate and TEF are found at gap spacing around $5 \%$ for $\mathrm{BR} \geq$ 0.10 , but around $30 \%$ for $\mathrm{BR}=0.05$. The $\mathrm{f} / \mathrm{f}_{0}$ with $\mathrm{GR}$ at $\mathrm{BR}=0.05,0.10$, $0.15,0.20,0.25$ and 0.30 is plotted as Figs. 26a, b, c, d, e and f, respectively, for $\alpha=45^{\circ}$. The highest pressure loss is detected at GR = 0.05 , except for $\mathrm{BR}=0.10$, which found at $\mathrm{GR}=0.10$.

At $\alpha=45^{\circ}$, the heat transfer rate is detected around $1.00-4.70,1.00$ $-6.80,1.40-11.70,1.50-14.00,2.00-15.50$ and $2.20-17.50$ times greater than the smooth channel with no baffle, respectively, for BR = $0.05,0.10,0.15,0.20,0.25$ and 0.30 . The $\mathrm{f} / \mathrm{f}_{0}$ at $\mathrm{BR}=0.05,0.10,0.15$, $0.20,0.25$ and 0.30 is about $1.00-6.50,1.30-15.30,2.00-34.50,4.00$ $-63.00,7.00-105.00$ and $15.00-220.00$, respectively, at $\alpha=45^{\circ}$. For $\alpha=45^{\circ}$, the maximum TEF is detected at $\mathrm{Re}=2000$ for all BRs around
$2.50,2.80,3.60,3.50,3.25$ and 2.90 , respectively, at $\mathrm{BR}=0.05,0.10$ $0.15,0.20,0.25$ and 0.30 .

In comparison, the heat exchanger section inserted with $\mathrm{C}$-shaped baffle performs higher TEF than the wavy surface vortex generators (Boonloi and Jedsadaratanachai (2019a), Boonloi and Jedsadaratanachai (2018a), Jedsadaratanachai and Boonloi (2017)) and V-shaped baffle (Boonloi and Jedsadaratanachai (2018b), (Boonloi and Jedsadaratanachai (2018c)). The C-shaped baffle provides similar value of TEF when compared with the V-orifice (Boonloi and Jedsadaratanachai (2019b)), but the pressure loss of the C-shaped baffle is lower than the V-orifice (Boonloi and Jedsadaratanachai (2019c)).

\section{CONCLUSION}

Numerical predictions on flow topology and heat transfer behavior in the heat exchanger square channel placed with $\mathrm{C}$-shaped baffle are performed. The influences of baffle height and position for placement in the channel are considered for the laminar flow regime with the Reynolds number around $100-2000$. The flow attack angles $\left(\alpha=30^{\circ}\right.$ and $\left.45^{\circ}\right)$ for the C-shaped baffle are also studied. The major findings of the present investigations can conclude as follows;

The C-shaped baffle can produce the vortex flow or swirling flow through the test section in all investigated cases. The vortex flow disturbs the thermal boundary layer on the heat transfer surface that the cause for heat transfer rate and thermal performance augmentations. The better fluid mixing in the test section is also detected when inserting the $\mathrm{C}$ shaped baffle in the test section.

The increment of the baffle height leads to higher heat transfer rate and pressure loss in the channel. The variation of the gap spacing value effects for the change of the heat transfer and flow patterns. The optimum gap value may support the enhancements of heat transfer rate and thermal efficiency. The difference of flow attack angles has no effect for heat transfer and flow configurations.

The best thermal performance is found at the BR of 0.20 and 0.15 for the flow attack angle of $30^{\circ}$ and $45^{\circ}$, respectively. The suggestion gap spacing between baffle and channel wall is around 5\%, which gives the optimum thermal enhancement factor for both attack angles.

\section{ACKNOWLEDGEMENTS}

The authors would like to thank Assoc. Prof. Dr. Pongjet Promvonge for suggestions. This research was funded by King Mongkut's University of Technology North Bangkok, Contract no. KMUTNB-63-KNOW-010.

BR flow blockage ratio $(=\mathrm{b} / \mathrm{H})$

\section{NOMENCLATURE}

b baffle height, $m$

$\mathrm{D}_{\mathrm{h}}$ hydraulic diameter of channel, $\mathrm{m}$

f friction factor

GR gap spacing ratio, $(=\mathrm{g} / \mathrm{H})$

$\mathrm{g} \quad$ gap spacing, $\mathrm{m}$

$\mathrm{H}$ channel height, $\mathrm{m}$

h convective heat transfer coefficient, $\mathrm{W} \mathrm{m}^{-2} \mathrm{~K}^{-1}$

$\mathrm{k}$ thermal conductivity, $\mathrm{W} \mathrm{m}^{-1} \mathrm{~K}^{-1}$

$\mathrm{Nu}$ Nusselt number $(=\mathrm{hD} / \mathrm{k})$

$\mathrm{P}$ pitch spacing, $\mathrm{m}$

$\mathrm{PR}$ pitch ratio $(=\mathrm{P} / \mathrm{H})$

$\mathrm{p}$ static pressure, $\mathrm{Pa}$

Pr Prandtl number $(\operatorname{Pr}=0.707)$

Re Reynolds number

$\mathrm{T}$ temperature, $\mathrm{K}$

$\mathrm{u}_{\mathrm{i}} \quad$ velocity in $\mathrm{x}_{\mathrm{i}}$-direction, $\mathrm{m} \mathrm{s}^{-1}$

$\bar{u}$ mean velocity in channel, $\mathrm{m} \mathrm{s}^{-1}$

\section{Greek letter}

$\alpha \quad$ flow attack angle, degree

TEF thermal enhancement factor $\left(=\left(\mathrm{Nu} / \mathrm{Nu}_{0}\right) /\left(\mathrm{f} / \mathrm{f}_{0}\right)^{1 / 3}\right)$

$\rho$ density, $\mathrm{kg} \mathrm{m}^{-3}$

\section{Subscript}


in inlet

0 smooth tube

pp pumping power

\section{REFERENCE}

Boonloi, A., 2014, "Effect of Flow Attack Angle of V-Ribs Vortex Generators in a Square Duct on Flow Structure, Heat Transfer, and Performance Improvement," Modelling and Simulation in Engineering, Article ID 985612, 11 pages.

http://dx.doi.org/10.1155/2014/985612

Boonloi, A., and Jedsadaratanachai, W., 2014, "Thermal Performance Analysis and Empirical Correlations for Laminar Forced Convection over 30॰ V-Baffled Square Channel," Advances in Mechanical Engineering, Article ID 930272, 16 pages. http://dx.doi.org/10.1155/2014/930272

Boonloi, A., and Jedsadaratanachai, W., 2016, "Numerical Investigation on Turbulent Forced Convection and Heat Transfer Characteristic in a Square Channel with Discrete Combined V-baffle and V-orifice," Case Studies in Thermal Engineering, 8, 226-235.

https://doi.org/10.1016/j.csite.2016.07.003

Boonloi, A., and Jedsadaratanachai, W., 2018a, "Numerical Prediction on Flow and Heat Transfer in Heat Exchanger Tube Equipped with Various Flow Attack Angles of Inclined-wavy Surface," Frontiers in Heat and Mass Transfer, 11 - 10.

http://dx.doi.org/10.5098/hmt.11.10

Boonloi, A., and Jedsadaratanachai, W., 2018b, "Effect of Location in Transverse Plane for 45-degree V-baffle on Flow and Heat Transfer Mechanisms in a Square Channel," Frontiers in Heat and Mass Transfer, $11-29$.

http://dx.doi.org/10.5098/hmt.11.29

Boonloi, A., and Jedsadaratanachai, W., 2018c, "Convective Heat Transfer, Friction Factor and Thermal Performance in a Round Tube Equipped with the Modified V-shaped Baffle," Frontiers in Heat and Mass Transfer, 10 - 6.

http://dx.doi.org/10.5098/hmt.10.6

Boonloi, A., and Jedsadaratanachai, W., 2019a, "Thermal Performance Improvement in a Square Channel Heat Exchanger with Various Parameter of V-wavy Plate," Frontiers in Heat and Mass Transfer, 12 1.

http://dx.doi.org/10.5098/hmt.12.1

Boonloi, A., and Jedsadaratanachai, W., 2019b, "The Effects of Gap Spacing Ratio on Flow Structure and Heat Transfer Characteristic for the V-Orifice in the Square Channel Heat Exchanger," Frontiers in Heat and Mass Transfer, 12 - 19.

http://dx.doi.org/10.5098/hmt.12.19

Cengel, Y.A., and Ghajar, A.J., 2015, "Heat and Mass Transfer: Fundamentals \& applications, Fifth edition in SI Units, McGraw-Hill Education, ISBN 978-981-4595-27-8

Gomaa, A., Halim, M.A., and Elsaid, A.M., 2017, "Enhancement of Cooling Characteristics and Optimization of a Triple Concentric-tube Heat Exchanger with Inserted Ribs," International Journal of Thermal Sciences, 120, 106-120.

https://doi.org/10.1016/j.ijthermalsci.2017.06.002

Hu, J., Liu, K., Ma, L., and Sun, X., 2018, "Parameter Optimization of Solar Air Collectors with Holes on Baffle and Analysis of Flow and Heat Transfer Characteristics," Solar Energy, 174, 878-887.

https://doi.org/10.1016/j.solener.2018.09.075

Jedsadaratanachai, W., and Boonloi, A., 2017, "Three-dimensional Numerical Investigation on Laminar Forced Convection and Heat Transfer in a Circular Tube Inserted with Right Triangular Wavy Surfaces," Frontiers in Heat and Mass Transfer, 8 - 35.

\section{http://dx.doi.org/10.5098/hmt.8.35}

Jedsadaratanachai, W., and Boonloi, A., 2014, "Effects of Blockage Ratio and Pitch Ratio on Thermal Performance in a Square Channel with $30^{\circ}$ Double V-baffles," Case Studies in Thermal Engineering, 4, 118128.

https://doi.org/10.1016/j.csite.2014.08.002

Jedsadaratanachai, W., Jayranaiwachira, N., and Promvonge, P., 2015, "3D Numerical Study on Flow Structure and Heat Transfer in a Circular Tube with V-baffles," Chinese Journal of Chemical Engineering, 23, 342-349.

https://doi.org/10.1016/j.cjche.2014.11.006

Kumar, A., and Layek, A., 2018a, "Nusselt Number-Friction Characteristic for a Twisted Rib Roughened Rectangular Duct using Liquid Crystal Thermography," Experimental Thermal and Fluid Science, 97, 205-217.

https://doi.org/10.1016/j.expthermflusci.2018.04.017

Kumar, R., Chauhan, R., Sethi, M., and Kumar, A., 2017a, "Experimental Study and Correlation Development for Nusselt Number and Friction Factor for Discretized Broken V-pattern Baffle Solar Air Channel," Experimental Thermal and Fluid Science, 81, 56-75. https://doi.org/10.1016/j.expthermflusci.2016.10.002

Kumar, R., Sethi, M., Chauhan, R., and Kumar, A., 2017b, "Experimental Study of Enhancement of Heat Transfer and Pressure Drop in a Solar Air Channel with Discretized Broken V-pattern Baffle," Renewable Energy, 101, 856-872.

https://doi.org/10.1016/j.renene.2016.09.033

Kumar, A., and Layek, A., 2018b, "Thermo-hydraulic Performance of Solar Air Heater having Twisted Rib over the Absorber Plate," International Journal of Thermal Sciences, 133, 181-195. https://doi.org/10.1016/i.ijthermalsci.2018.07.026

Li, J.L., Tang, H.W., and Yang, Y.T., 2018, "Numerical Simulation and Thermal Performance Optimization of Turbulent Flow in a Channel with Multi V-shaped Baffles," International Communications in Heat and Mass Transfer, 92, 39-50.

https://doi.org/10.1016/j.icheatmasstransfer.2018.02.004

Menasria, F., Zedairia, M., and Moummi, A., 2017, "Numerical Study of Thermohydraulic Performance of Solar Air Heater Duct Equipped with Novel Continuous Rectangular Baffles with High Aspect Ratio," Energy, 133, 593-608.

https://doi.org/10.1016/j.energy.2017.05.002

Patankar, S.V., Liu, C.H., and Sparrow, E.M., 1998, "Fully Developed Flow and Heat Transfer in Ducts having Streamwise-periodic Variations of Cross-sectional Area, ASME Journal of Heat Transfer, 98, 11091151.

https:// doi:10.1115/1.3450666

Promvonge, P., 2010, "Heat Transfer and Pressure Drop in a Channel with Multiple $60^{\circ} \mathrm{V}$-baffles," International Communications in Heat and Mass Transfer, 37, 835-840.

https://doi.org/10.1016/j.icheatmasstransfer.2010.04.003

Promvonge, P., and Kwankaomeng, S., 2010, "Periodic Laminar Flow and Heat Transfer in a Channel with $45^{\circ}$ Staggered V-baffles," International Communications in Heat and Mass Transfer, 37, 841-849. https://doi.org/10.1016/j.icheatmasstransfer.2010.04.002

Promvonge, P., Jedsadaratanachai, W., Kwankaomeng, S., and Thianpong, C., 2012, "3D Simulation of Laminar Flow and Heat Transfer in V-baffled Square Channel," International Communications in Heat and Mass Transfer, 39, 85-93.

https://doi.org/10.1016/j.icheatmasstransfer.2011.09.004 